\title{
PRISMA-S: an extension to the PRISMA statement for reporting literature searches in systematic reviews*
}

\author{
Melissa L. Rethlefsen, AHIP; Shona Kirtley; Siw Waffenschmidt; Ana Patricia Ayala, AHIP; David Moher; Matthew J. \\ Page; Jonathan B. Koffel; PRISMA-S Group
}

See end of article for authors' affiliations.

\begin{abstract}
Background: Literature searches underlie the foundations of systematic reviews and related review types. Yet, the literature searching component of systematic reviews and related review types is often poorly reported. Guidance for literature search reporting has been diverse and, in many cases, does not offer enough detail to authors who need more specific information about reporting search methods and information sources in a clear, reproducible way. This document presents the PRISMA-S (Preferred Reporting Items for Systematic reviews and Meta-Analyses literature search extension) checklist, and explanation and elaboration.
\end{abstract}

Methods: The checklist was developed using a three-stage Delphi survey process, followed by a consensus conference and public review process.

Results: The final checklist includes sixteen reporting items, each of which is detailed with exemplar reporting and rationale.

Conclusions: The intent of PRISMA-S is to complement the PRISMA Statement and its extensions by providing a checklist that could be used by interdisciplinary authors, editors, and peer reviewers to verify that each component of a search is completely reported and, therefore, reproducible.

Keywords: systematic reviews; reporting guidelines; search strategies; literature search; information retrieval; reproducibility

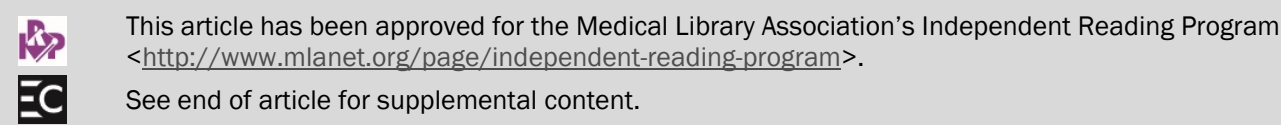

\section{INTRODUCTION}

One crucial component of a systematic review is the literature search. The literature search, or information retrieval process, not only informs the results of a systematic review, it is the underlying process that establishes the data available for analysis. Additional components of the systematic review process such as screening, data extraction, and qualitative or quantitative synthesis procedures are dependent on the identification of eligible studies. As such, the literature search must be designed to be both robust and reproducible to ensure the minimization of bias.

Guidelines exist for both the conduct of literature searches (Box 1) for systematic reviews and their reporting [1-6]. Problematically, however, the many guidelines for reporting systematic review searches share few common reporting elements. In fact, Sampson et al. discovered that of eleven instruments designed to help authors report literature searches well, only one item appeared in all eleven instruments [7]. Though Sampson et al.'s study was conducted in 2007 , the problem has only

\footnotetext{
* In order to encourage broad adoption of PRISMA-S, this article will also be published in Systematic Reviews (https://doi.org/10.1186/s13643-02001542-z).
} 
been compounded as new checklists and tools have continued to be developed. The most commonly used reporting guidance for systematic reviews, which covers the literature search component, is the Preferred Reporting Items for Systematic reviews and MetaAnalyses Statement, or PRISMA Statement [8]. The 2009 PRISMA Statement checklist included three items related to literature search reporting, items 7, 8, and 17:

Item 7: Describe all information sources (e.g., databases with dates of coverage, contact with study authors to identify additional studies) in the search and date last searched.

Item 8: Present full electronic search strategy for at least one database, including any limits used, such that it could be repeated.

Item 17: Give numbers of studies screened, assessed for eligibility, and included in the review, with reasons for exclusions at each stage, ideally with a flow diagram.

Despite wide usage of the PRISMA Statement [9], compliance with its items regarding literature search reporting is low [10-13]. Even for those studies which explicitly reference PRISMA, there is only slight, statistically non-significant evidence of improved reporting, as found by Page et al. [14]. Part of the challenge may be the multifactorial nature of each of the PRISMA items relating to searches; authors may feel if they completed one of the components of the item, that they can check off that item altogether. Another part of the challenge may be that many systematic reviews do not include librarians or information specialists as members of the systematic review team or as authors on the final manuscript [10,15-17]. Preliminary research suggests that librarian or information specialist involvement is correlated with reproducibility of searches [15-17], likely due to their expertise surrounding search development and documentation. However, reviews where librarians are authors still include reproducible searches only $64 \%$ of the time [16].

A larger issue may be that, even amongst librarians and information specialists, debate exists as to what constitutes a reproducible search and how best to report the details of the search. Researchers assessing the reproducibility of the search have used varying methods to determine what constitutes a reproducible search [10, $16,18,19]$. Post-publication peer review of search methods, even amongst Cochrane reviews, which generally have superior reporting compared to nonCochrane reviews [14], has shown that reporting that appears complete may still pose challenges for those wishing to reproduce searches [19-23]. Furthermore, little guidance on how to report searches using information sources or methods other than literature databases, such as searching websites or study registries, exists [24, 25].
Incomplete reporting of the literature search methods can introduce doubt and diminish trust in the final systematic review conclusions. If researchers are unable to understand or reproduce how information was gathered for a systematic review, they may suspect the authors of having introduced bias into their review by not conducting a thorough or pre-specified literature search. After observing the high number of systematic reviews with poorly reported literature searches, we sought to create an extension to the PRISMA statement. Our aims were fourfold:

1. To provide extensive guidance on reporting the literature search components of a systematic review.

2. To create a checklist that could be used by authors, editors, and peer reviewers to verify that each component of a search was completely reported and, therefore, reproducible.

3. To develop an interdisciplinary checklist applicable to all methods-driven literature searches for evidence synthesis.

4. To complement the PRISMA Statement and its extensions.

Because we intend the checklist to be used in all fields and disciplines, we use "systematic reviews" throughout this document as a representative name for the entire family of evidence syntheses [26]. This includes, but is not limited to, scoping reviews, rapid reviews, realist reviews, metanarrative reviews, mixed methods reviews, umbrella reviews, and evidence maps [27]. We use the term "literature search" or "search" throughout to encompass the full range of possible search methods and information sources.

\section{PART 1. DEVELOPING THE CHECKLIST}

After consultation with members of the PRISMA Statement steering group (Moher and Altman), we formed an executive committee (Rethlefsen, Koffel, Kirtley) and developed a protocol [28] according to the steps outlined in "Guidance for Developers of Health Research Reporting Guidelines" [29]. The protocol was registered on the EQUATOR Network [28]. We identified 405 potential items relevant to reporting searches in systematic reviews from 61 sources (see supplemental Appendix A) located through a search of MEDLINE via Ovid, Embase via Embase.com, and LISTA via EBSCOhost, in addition to reviewing all of the sources identified by the EQUATOR Network relating to systematic reviews. We also searched our personal files and examined references of included documents for additional sources. Details of the search are available in supplemental Appendix A. Sources included both explicit reporting guidelines and studies assessing reproducibility of search strategies. The 405 items were reviewed for overlap and consolidated into 123 remaining items for potential inclusion in a checklist. 
To narrow the list into a usable checklist, we then used a 3-step Delphi survey process [30]. The first survey included the initially identified 123 items and asked respondents to rate each item on a 4-point Likert-type scale. Items that $70 \%$ of experts rated as 3 or 4 (4 being "essential" and 1 "not important") and that received a mean score of at least 3.25 were retained for rating in the second round of the Delphi process. Respondents to the first survey were invited to participate in the second and third rounds. The second round asked respondents to pick the 25 most essential items out of the remaining 53 potential items; the third round was identical, except respondents also selected the most appropriate location for reporting their selected items (e.g., in the main text, or a supplementary file). The items were ranked and categorized by general theme for discussion at an inperson consensus conference.

We created a list of 163 international experts including librarian and information specialists with expertise in systematic reviews, researchers who had written about systematic review reporting, journal editors, and systematic review methodologists - to whom we sent our initial Delphi survey. The list of experts was created using a combination of publications, mailing lists, conference proceedings, and knowledge of the authors to represent research groups and experts in 23 countries. We received 52 responses ( $32 \%$ response rate) to the first survey, and of these, 35 (67\% response rate) completed both surveys two and three. This study was declared exempt by the University of Utah Institutional Review Board (IRB_00088425).

The results of the Delphi process were reported at a consensus conference meeting that took place in May 2016 concurrently with Mosaic '16, the joint meeting of the Medical Library Association (MLA), Canadian Health Libraries Association/ Association des bibliothèques de la santé du Canada, and the International Clinical Librarian Conference (ICLC). Thirty-eight individuals attended the consensus conference, 14 (37\%) of whom had participated in the Delphi surveys. At the consensus conference, the grouped and ranked remaining items were distributed to small groups who were asked to discuss, consolidate, remove, or add missing critical items under the guidance of a group leader. After two rounds of discussion, the group leaders presented the discussion and proposed list items from their small groups for consideration by the whole group of experts.

Upon completion of the consensus conference, 30 items remained from those identified during the Delphi process, with an additional three items that had been excluded during the Delphi process added back to the draft checklist because meeting attendees considered them critical to the guideline. The list was then consolidated and reviewed by executive committee members, including two new information specialist members (Waffenschmidt and Ayala). The draft checklist and explanation and elaboration document was released to the public on March 20, 2019, along with all data and study materials [31]. All participants in the Delphi process and/or consensus conference were contacted via email with instructions on how to provide feedback on the draft checklist items and/or elaboration and explanation document by commenting directly on the explanation and elaboration draft using a private commenting system, Hypothesis [32], or if preferred, via email. Comments from other interested individuals were solicited via Twitter, conference presentations, and personal contacts. Comments were collected from the private Hypothesis group, the public Hypothesis comments, and via email. All comments were combined into a single document. Executive committee members reviewed each comment in duplicate to indicate what type of feedback was received (i.e., linguistic, major substantive, minor substantive, or unclear) and, for substantive comments, whether change was recommended or required further discussion.

During the draft and revision process (March 20-June 15, 2019), 358 separate comments were received from 22 individuals and organizations. Based upon the extensive feedback received, the executive team revised the checklist and developed the next iteration, which was released on December 6, 2019, to coincide with the 2019 Virtual Cochrane Colloquium Santiago. Additional feedback from this release was incorporated into the final checklist. Throughout the draft and revision process, several teleconferences were held with the lead of the PRISMA 2020 statement (Page), as an update of the 2009 PRISMA statement was in development, to ensure that the content on search methods was consistent between the PRISMA 2020 and PRISMA-S guidelines [33, 34].

\section{PART 2. CHECKLIST}

PRISMA-S is a sixteen-item checklist that covers multiple aspects of the search process for systematic reviews (Table 1 ). It is intended to guide reporting, not conduct, of the search. The checklist should be read in conjunction with the explanation and elaboration (Part 3), which provides more detail about each item. We also include two boxes, one a glossary of terms (see Box 1) and the other, guidance on depositing search data and methods descriptions in online repositories (see Box 2).

The explanation and elaboration also includes examples of good reporting for each item. Each exemplar is drawn from published systematic reviews. For clarity, some exemplars are edited to match the style of this document, including any original citations, and abbreviations are spelled out to aid comprehension. Any other edits to the text are noted with square brackets. A description of the rationale behind the item are explained, followed by additional suggestions for clear reporting and a suggested location(s) for reporting the item. 
Not every systematic review will make use of all of the items in the Information Sources and Methods section of the checklist, depending on the research question and the methods chosen by the authors. The checklist provides a framework for the current most common and recommended types of information sources and methods for systematic reviews, but authors should use and report those items relevant and appropriate to their review. The checklist may also be used for systematic review protocols to fully document the planned search, in conjunction with the PRISMA-P reporting guideline [35].

Table 1 PRISMA-S checklist

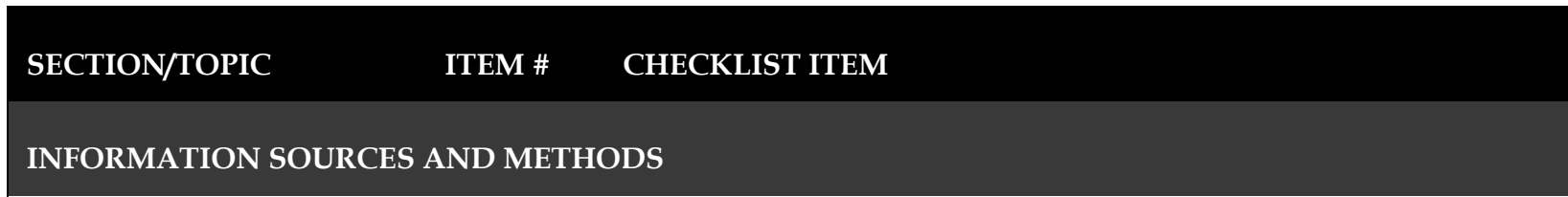
Database name
1 Name each individual database searched, stating the platform for each.

Multi-database searching

2 If databases were searched simultaneously on a single platform, state the name of the platform, listing all of the databases searched.

Study registries

3 List any study registries searched.

Online resources and browsing

Citation searching

Other methods

Contacts
Describe any online or print source purposefully searched or browsed (e.g., tables of contents, print conference proceedings, websites), and how this was done.

5 Indicate whether cited references or citing references were examined and describe any methods used for locating cited/citing references (e.g., browsing reference lists, using a citation index, setting up email alerts for references citing included studies).

6 Indicate whether additional studies or data were sought by contacting authors, experts, manufacturers, or others.

\section{SEARCH STRATEGIES}

Full search strategies

8 Include the search strategies for each database and information source, copied and pasted exactly as run.

Limits and restrictions

9 Specify that no limits were used, or describe any limits or restrictions applied to a search (e.g., date or time period, language, study design) and provide justification for their use. 
DOI: dx.doi.org/10.5195/jmla.2021.962

Table 1 PRISMA-S checklist (continued)

\begin{tabular}{|c|c|c|}
\hline Search filters & 10 & $\begin{array}{l}\text { Indicate whether published search filters were used (as originally } \\
\text { designed or modified), and if so, cite the filter(s) used. }\end{array}$ \\
\hline Prior work & 11 & $\begin{array}{l}\text { Indicate when search strategies from other literature reviews were } \\
\text { adapted or reused for a substantive part or all of the search, citing the } \\
\text { previous review(s). }\end{array}$ \\
\hline Updates & 12 & $\begin{array}{l}\text { Report the methods used to update the search(es) (e.g., rerunning } \\
\text { searches, email alerts). }\end{array}$ \\
\hline Dates of searches & 13 & $\begin{array}{l}\text { For each search strategy, provide the date when the last search } \\
\text { occurred. }\end{array}$ \\
\hline \multicolumn{3}{|l|}{ PEER REVIEW } \\
\hline Peer review & 14 & Describe any search peer review process. \\
\hline \multicolumn{3}{|c|}{ MANAGING RECORDS } \\
\hline Total records & 15 & $\begin{array}{l}\text { Document the total number of records identified from each database } \\
\text { and other information sources. }\end{array}$ \\
\hline Deduplication & 16 & $\begin{array}{l}\text { Describe the processes and any software used to deduplicate records } \\
\text { from multiple database searches and other information sources. }\end{array}$ \\
\hline
\end{tabular}

A downloadable version of the checklist is available on the PRISMA website [36].

\section{PART 3: EXPLANATION AND ELABORATION}

\section{ITEM 1. Database name}

Name each individual database searched, stating the platform for each.

\section{Example.}

"The following electronic databases were searched: MEDLINE (Ovid), CINAHL (EBSCOhost), PsycINFO (Ovid), Cochrane Central Register of Controlled Trials (Ovid), SPORTDiscus (EBSCOhost), EMBASE (Ovid) and ProQuest Dissertations and Theses Global (ProQuest)." [37]

\section{Explanation.}

Databases are the most commonly used tool to locate studies to include in systematic reviews and metaanalyses $[5,38]$. There is no single database that is able to provide a complete and accurate list of all studies that meet systematic review criteria due to the differences in the articles included and the indexing methods used between databases (Box 1). These differences have led to recommendations that systematic review teams search multiple databases to maximize the likelihood of finding relevant studies $[5,38,39]$. This may include using broad disciplinary databases (e.g., MEDLINE [40], Embase [41] Scopus [42]), specialized databases (e.g., PsycInfo [43] or EconLit [44]), or regional databases (e.g., LILACS [45] or African Index Medicus [46]).

Many of these literature databases are available through multiple different search platforms (Box 1). For example, the MEDLINE database is available through at least 10 different platforms, including Ovid, EBSCOhost, Web of Science, and PubMed. Each platform offers different ways of searching the databases, such as platform-specific field codes (Box 1), phrase searching, truncation, or searching full-text versus abstract and keyword only [47]. Different platforms may contain additional data that are not available in the original 
database, such as times cited, social media impact, or additional keywords. These differences between the platforms can have a meaningful impact on the results provided [47-49].

Authors should identify which specific literature databases were searched to locate studies included in the systematic review. It is important that authors indicate not only the database, but the platform through which the database was searched. This helps readers to evaluate the quality and comprehensiveness of the search and supports reproducibility and updating (Box 1) in the future by allowing the strategy to be copied and pasted as recommended in Item 8 , below.

The distinctions between database and platform may not always be clear to authors, especially when the database is the only one available through a platform (e.g., Scopus [42]). In these cases, authors may choose to include the web address of the database in the text or the bibliography to provide clarity for their readers.

Suggested location for reporting

Report each database name and platform in the methods section and any supplementary materials (Box 1). If space permits, report key database names in the abstract.

\section{ITEM 2. Multi-database searching}

If databases were searched simultaneously on a single platform, state the name of the platform, listing all of the databases searched.

\section{Examples.}

"The MEDLINE and Embase strategies were run simultaneously as a multi-file search in Ovid and the results de-duplicated using the Ovid de-duplication tool." [50]

"A systematic literature search was performed in Web of Knowledge ${ }^{\mathrm{TM}}$ (including KCI Korean Journal Database, MEDLINE, Russian Science Citation Index, and SciELO Citation Index)." [51]

\section{Explanation.}

Authors may choose to search multiple databases at once through a single search platform to increase efficiency. Along with the name of the platform, it is necessary to list the names of each of the individual databases included as part of the search. Including information about using this approach in the text of the manuscript helps readers immediately understand how the search was constructed and executed. This helps readers determine how effective the search strategy (Box 1) will be for each database [52].

\section{Suggested location for reporting}

Report any multi-database search (Box 1) in the methods section and any supplementary materials. If space permits, report key individual database names in the abstract, even if run through a multi-database search.

\section{ITEM 3. Study registries}

List any study registries searched.

Example.

"[We] searched several clinical trial registries (ClinicalTrials.gov, Current Controlled Trials (www.controlled-trials.com), Australian New Zealand Clinical Trials Registry (www.actr.org.au), and University Hospital Medical Information Network Clinical Trials Registry (www.umin.ac.jp/ctr)) to identify ongoing trials." [53]

\section{Explanation.}

Study registries are a key source of information for systematic reviews and meta-analyses in the health sciences and increasingly in other disciplines. In the health sciences, study registries (Box 1) allow researchers to locate ongoing clinical trials and studies that may have gone unpublished [54-56]. Some funders, including the National Institutes of Health, require principal investigators to share their data on study registries within a certain time frame after grant completion [57]. This data may not have been published in any other location, making study registries a critical component of an information strategy, though timely reporting remains a challenge [58,59]. Different countries have their own study registries, as do many pharmaceutical companies.

Outside the health sciences, study registries are becoming increasingly important as many disciplines adopt study preregistration as a tactic for improving the rigor of research. Though not yet as established as in the health sciences, these study registries are continually expanding and will serve as key sources for finding unpublished studies in fields in the social sciences and beyond.

To fully describe the study registries searched, list the name of each study registry searched and include a citation or link to the study registry.

Suggested location for reporting

Report any study registries searched in the methods section and any supplementary materials.

\section{ITEM 4. Online resources and browsing}

Describe any online or print source purposefully searched or browsed (e.g., tables of contents, print conference proceedings, websites), and how this was done.

\section{Examples.}

"We also searched the grey literature using the search string: "public attitudes" AND "sharing" AND "health data" on Google (in June 2017). The first 20 results were selected and screened." [60] 
"The grey literature search was conducted in October 2015 and included targeted, iterative hand searching of 22 government and/or research organization websites that were suggested during the expert consultation and are listed in S1 Protocol. Twenty two additional citations were added to the review from the grey literature search." [61]

"To locate unpublished studies, we searched Embase [via Embase.com] for conference proceedings since 2000 and handsearched meeting abstracts of the Canadian Conference on Physician Health and the International Conference on Physician Health (2012 to 2016)." [62]

\section{Explanation.}

Systematic reviews were developed to remove as much bias as possible from the literature review process. One of the most important ways they achieve this reduction in bias is by searching beyond literature databases, which are skewed toward English-language publications with positive results $[63,64]$. To achieve a fuller picture of what the research on a specific topic looks like, systematic reviewers could seek out research that may be in progress and research that was never published [5]. Using other methods of finding research also helps identify research that may have been indexed in literature databases but went undiscovered when searching those sources [39]. Seeking out this research often involves a complex strategy, drawing on a wealth of online and print resources as well as personal contacts.

Web search engines and specific websites. Searching general Internet search engines and searching the contents of specific websites is a key component of many systematic reviews [25, 65]. Government, nonprofit organization, and pharmaceutical company websites, for example, contain a wealth of information not published elsewhere [5, 66]. Though searching a general search engine like Google or using a general search engine to search a specific website may introduce some bias into the search methodology through the personalization algorithms inherent in many of these tools $[67,68]$, it is still important to fully document how web searches were conducted [65].

Authors should list all websites searched, along with their corresponding web address. Readers should be able to clearly understand if researchers used a website's native search interface or advanced search techniques within a general search engine. If authors used a general search engine, authors should declare whether steps were taken to reduce personalization bias (e.g., using "incognito" mode in a browser). Authors may choose whether to detail the websites searched within the text (i.e., Google <http:/ / www.google.com>), by citing the websites in the bibliography, or by listing the website with corresponding web address in supplementary material, as shown in the examples above.

Review teams may occasionally set an artificial limit to the number of items they will screen from a given search or source [65]. This is because searching web search engines and individual websites will often lead to an unmanageable number of results, the search engine itself may only display a restricted number of results (e.g., Google will only display 1,000 results), or the team has a finite budget or timeline to complete the review. Thus, many systematic review teams utilizing web search engines will often pre-designate a limit to the number of results they review. If review teams choose to review a limited set of results, it should be noted in the text, along with the rationale.

Conference proceedings. Studies show that large percentages of research presented as papers and posters at conferences never make their way into the published literature, particularly if the study's results were statistically negative $[63,69]$. Conference proceedings are often the only way to locate these studies. Including conference proceedings in a systematic review search helps minimize bias [70]. The introduction of online conference proceedings has been a boon to researchers and reduced the need to review printed abstract books. Additionally, some databases either include conference proceedings along with journal articles (i.e., Embase [41]) or contain only conference proceedings (i.e., ProceedingsFirst [71] or Directory of Published Papers [72]). Some conferences have made their abstracts available in a single database (i.e., International AIDS Society's Abstract Archive [73]). When using these types of databases to search conference proceedings, authors can treat them as above in Item 1.

Individual conferences' online proceedings may be password-protected for association members or conference attendees [74]. When reporting on conference proceedings searched or browsed (Box 1) via a conference or association's online or print proceedings, authors must specify the conference names, the dates of conferences included, and the method used to search the proceedings (i.e., browsing print abstract books or using an online source). If the conference proceedings are searched online, authors should specify the web address(es) for the conference proceedings and the date(s) of the conferences. If the conference proceedings are published in a journal, the authors should cite the journal. If the proceedings are a standalone publication, authors may choose to cite them using the same methods used to cite a book or by providing the full information about the conference (name, location, dates, etc.) in a supplementary file.

General browsing. Authors also commonly browse print or online tables of contents, full contents of journals, or other sources that are the most likely to contain research on the topic sought. When purposefully browsing, describe any method used, the name of the journal or other source, and the time frame covered by the search, if applicable.

Suggested location for reporting

Report online information sources (Box 1) searched or browsed in the methods section and in any supplementary materials. Systematic reviews using several of these 
methods, or using multiple information sources for each method, may need to report their methods briefly in the methods section, but should fully report all necessary information to describe their approaches in supplementary materials.

\section{ITEM 5. Citation searching}

Indicate whether cited references or citing references were examined, and describe any methods used for locating cited/citing references (e.g., browsing reference lists, using a citation index, setting up email alerts for references citing included studies).

\section{Examples.}

"Reference lists of included articles were manually screened to identify additional studies." [75]

"[W]e used all shared decision making measurement instruments that were identified in Gärtner et al's recent systematic review (Appendix A). We then performed a systematic citation search, collecting all articles that cited the original papers reporting on the development, validation, or translation of any the observational and/or self-reported shared decision making measurement instruments identified in that review. An experienced librarian (P.J.E.) searched Web of Science [Science Citation Index] and Scopus for articles published between January 2012 and February 2018." [76]

"We [conducted] citation tracking of included studies in Web of Science Core Collection on an ongoing basis, using citation alerts in Web of Science Core Collection." [77]

\section{Explanation.}

One of the most common search methods is reviewing the references or bibliographies of included studies [10, 16]. This type of citation searching (looking for cited references) can be additive to other cited reference searching methods, such as examining bibliographies of relevant systematic reviews. In addition, researchers may choose to look for articles that cite specified studies [78]. This may include looking beyond one level forwards and backwards (e.g., examining the bibliographies of articles cited by specified articles) [78]. Looking at bibliographies of included articles or other specified articles is often conducted by examining full-text articles, but it can also be accomplished using online tools called citation indexes (Box 1).

The use of these methods can be complicated to describe, but the explanation should clearly state the database used, if applicable (i.e., Scopus, Google Scholar, Science Citation Index), and describe any other methods used. Authors also must cite the "base" article(s) that citation searching was performed upon, either for examining cited or citing articles (Box 1 ). If the same database is used for both a topical search as well as citation searching, describe each use separately. For manually checking the reference lists for included articles, a simple statement as in the first example is sufficient.

\section{Suggested location for reporting}

Report citation searching details in the methods section and in any supplementary materials.

\section{ITEM 6. Contacts}

Indicate whether additional studies or data were sought by contacting authors, experts, manufacturers, or others.

\section{Examples.}

"We contacted representatives from the manufacturers of erythropoietin-receptor agonists (Amgen, Ortho-Biotech, Roche), corresponding or first authors of all included trials and subjectarea experts for information about ongoing studies." [79]

"We also sought data via expert requests. We requested data on the epidemiology of injecting drug use and blood-borne viruses in October, 2016, via an email distribution process and social media. This process consisted of initial emails sent to more than 2000 key experts and organisations, including contacts in the global, regional, and country offices of WHO, UNAIDS, Global Fund, and UNODC (appendix p 61). Staff in those agencies also forwarded the request to their colleagues and other relevant contacts. One member of the research team (SL) posted a request for data on Twitter, which was delivered to 5525 individual feeds (appendix p 62)." [80]

\section{Explanation.}

Contacting manufacturers (e.g., pharmaceutical companies), or reaching out to authors or experts directly or through organizations, is a key method to locate unpublished and ongoing studies [5]. Contacting authors or manufacturers may also be necessary when publications, conference proceedings, or clinical trials registry records do not provide the complete information needed $[63,81]$. Contacting manufacturers or regulating agencies might be required to acquire complete trial data from the clinical study reports [82, 83]. More broad calls for evidence may also be conducted when no specific groups or individuals are targeted.

Contact methods may vary widely, depending on the context, and may include personal contact, web forms, email mailing lists, mailed letters, social media contacts, or other methods. As these strategies are inherently difficult to reproduce, researchers should attempt to give as much detail as possible on what data or information was sought, who or what group(s) provided data or information, and how the individuals or groups were identified.

\section{Suggested location for reporting}

Report information about contacts to solicit additional information in the methods section and in any supplementary materials. Systematic reviews using elaborate calls for evidence or making extensive use of contacts as an information source may need to report their 
methods briefly in the methods section, but should fully report all necessary information to describe their approaches in supplementary materials.

\section{ITEM 7. Other methods}

Describe any additional information sources or search methods used.

\section{Examples.}

“We also searched... our personal files." [84]

"PubMed's related articles search was performed on all included articles." [85]

A thorough systematic review may utilize many additional methods of locating studies beyond database searching, many of which may not be reproducible methods. A key example is searching personal files. Another is using databases' built in tools, such as PubMed's Related Articles feature [86] or Clarivate Analytics' Web of Science's Related Records feature [87], to locate relevant articles based on commonalities with a starting article. Because these tools are often proprietary and their algorithms opaque, researchers may not be able to replicate the exact results at a later date. To attempt to be as transparent as possible, researchers should both note the tool that was used and cite any articles these operations were run upon. For all "other" methods, it is still important to declare that the method was used, even if it may not be fully replicable.

Suggested location for reporting

Report information about any other additional information sources or search methods used in the methods section and in any supplementary materials.

\section{ITEM 8. Full search strategies}

Include the search strategies for each database and information source, copied and pasted exactly as run.

\section{Examples.}

Database search. Methods section description. "The reproducible searches for all databases are available at DOI:10.7302/Z2VH5M1H." [88]

Database search. One of the full search strategies from supplemental materials in online repository. "Embase.com (692 on Jan 19, 2017)

1. 'social media'/exp OR (social NEAR/2 (media* OR medium* OR network*)):ti OR twitter:ti OR youtube:ti OR facebook:ti OR linkedin:ti OR pinterest:ti OR microblog*:ti OR blog:ti OR blogging:ti OR tweeting:ti OR 'web 2.0':ti

2. 'professionalism'/exp OR 'ethics'/exp OR 'professional standard'/de OR 'professional misconduct'/de OR ethic*:ab,ti OR unprofessional $^{*}$ ab,ti OR professionalism:ab,ti OR (professional*
NEAR/3 (standard* OR misconduct)):ab,ti OR ((professional OR responsib*) NEAR/3 (behavi* OR act OR conduct $\left.\left.^{*}\right)\right)$ :ab,ti

3. \#1 AND \#2 AND [english]/lim NOT ('conference abstract':it OR 'conference paper':it) [88]

Online resources and browsing. Methods section description. "The approach to study identification from this systematic review is transparently reported in the Electronic Supplementary Material Appendix S1." [89]

Online resources and browsing. One of the full online resource search strategies reported in supplement. "Date: 12/01/16. Portal/URL: Google. https://www.google.co.uk/webhp?hl=en. Search terms: ((Physical training) and (man or men or male or males) and (female or females or women or woman) and (military)). Notes: First 5 pages screened on title ( $n=50$ records)." [89]

\section{Explanation.}

Systematic reviews and related review types rely on thorough and complex search strategies to identify literature on a given topic. The search strategies used to conduct this data gathering are essential to the transparency and reproducibility of any systematic review. Without being able to assess the quality of the search strategies used, readers are unable to assess the quality of the systematic review $[8,10,16]$.

When space was at a premium in publications, complete reporting of search strategies was a challenge. Because it was necessary to balance the need for transparency with publication restrictions, previous PRISMA guidelines recommended including the complete search strategy from a minimum of one database searched [8]. Many systematic reviews, therefore, reported only the minimum necessary. However, reporting only selected search strategies can contribute to the observed irreproducibility of many systematic reviews $[10,16]$.

The prior versions of PRISMA did not elaborate on methods for reporting search strategies outside of literature databases. Subsequent to its publication, many groups have begun identifying the challenges of fully documenting other types of search methods [90,91]. Now recommended is the explicit documentation of all of the details of all search strategies undertaken [91, 92]. These should be reported to ensure transparency and maximum reproducibility, including searches and purposeful browsing activities undertaken in web search engines, websites, conference proceedings databases, electronic journals, and study registries.

Journal restrictions vary, but many journals now allow authors to publish supplementary materials with their manuscripts. At minimum, all search strategies, including search strategies for web search engines, websites, conference proceedings databases, electronic journals, and study registries, should be submitted as a supplement for publication. Though most supplements are appropriately accessible on journal publishers' 
websites as submitted, supplements may disappear [16]. In addition, many supplements are only available to journal subscribers [93]. Similarly, manuscripts available on public access systems like PubMed Central [94] may not have the corresponding supplemental materials properly linked. For optimal accessibility, authors should upload complete documentation to a data repository (Box 1), an institutional repository, or other secure and permanent online archive instead of relying on journal publication (see Box 2 for additional information).

It is important to document and report the search strategy exactly as run, typically by copying and pasting the search strategy directly as entered into the search platform. This is to ensure that information such as the fields searched, term truncation, and combinations of terms (i.e., Boolean logic or phrases) are accurately recorded. Many times, the copied and pasted version of a search strategy will also include key information such as limits (see Item 9; Box 1) used, databases searched within a multi-database search, and other database-specific detail that will enable more accurate reporting and greater reproducibility. This documentation must also repeat the database or resource name, database platform or web address, and other details necessary to clearly describe the resource.

\section{Suggested location for reporting}

Report the full search strategy in supplementary materials as described above. Describe and link to the location of the supplementary materials in the methods section.

\section{ITEM 9: Limits and restrictions}

Specify that no limits were used, or describe any limits or restrictions applied to a search (e.g., date or time period, language, study design) and provide justification for their use.

\section{Examples.}

No limits. "We imposed no language or other restrictions on any of the searches." [95]

Limits described without justification. "The search was limited to the English language and to human studies." [96]

\footnotetext{
"The following search limits were then applied: randomized clinical trials (RCTs) of humans 18 years or older, systematic reviews, and meta-analyses." [97]

Limits described with justification. "The search was limited to publications from 2000 to 2018 given that more contemporary studies included patient cohorts that are most reflective of current co-morbidities and patient characteristics as a result of the evolving obesity epidemic." [98]
}

Limits described, one with justification. "Excluded publication types were comments, editorials, patient education handouts, newspaper articles, biographies, autobiographies, and case reports. All languages were included in the search result; nonEnglish results were removed during the review process.... To improve specificity, the updated search was limited to human participants." [99]

\section{Explanation.}

Many databases have features that allow searchers to quickly restrict a search using limits. What limits are available in a database are unique to both the database and the platform used to search it. Limits are dependent on the accuracy of the indexer, the timeliness of indexing, and the quality of any publisher-supplied data. For instance, using database limits to restrict searches to randomized controlled trials will only find records identified by the indexer as randomized controlled trials. Since the indexing may take six months or more to complete for any given article, searchers risk missing new articles when using database limits.

Using database-provided limit features should not be confused with using filters (see Item 10; Box 1) or inclusion criteria for the systematic review. For example, systematic review teams may choose to only include English-language randomized controlled trials. This can be done using limits, a combination of a filter (see Item 10) and screening, or screening alone. It should be clear to the reader which approach is used. For instance, in the "Limits described, with one justification" example above, the authors used database limits to restrict their search by publication type, but they did not use database limits to restrict by language, even though that was a component of their eligibility criteria. They also used database limits to restrict to human participants in their search update.

It is important for transparency and reproducibility that any database limits applied when running the search are reported accurately, as their use has high potential for introducing bias into a search [52, 64, 100, 101]. Database limits are not recommended for use in systematic reviews, due to their fallibility $[38,100]$. If used, review teams should include a statement of justification for each use of a database limit in the methods section, the limitations section, or both $[102,103]$. In the examples above, only the last two examples provide some justification in the methods section ("to improve specificity" [99] and "contemporary studies included patient cohorts that are most reflective of current co-morbidities and patient characteristics as a result of the evolving obesity epidemic" [98]).

\section{Suggested location for reporting}

Report any limits or restrictions used or that no limits were used in the abstract, in the methods section, and in any supplementary materials, including the full search strategies (Item 8). Report the justification for any limits used within the methods section and/or in the limitations section. 


\section{ITEM 10. Search filters}

Indicate whether published search filters were used (as originally designed or modified), and if so, cite the filter(s) used.

\section{Example.}

“For our MEDLINE search we added a highly sensitive filter for identifying randomised trials developed by the Cochrane Collaboration [38]. For Embase we used the filter for randomised trials proposed by the Scottish Intercollegiate Guidelines Network [104]." [105]

\section{Explanation.}

Filters are a predefined combination of search terms developed to identify references with a specific content, such as a particular type of study design (e.g., randomized controlled trials) [106], populations (e.g., the elderly), or a topic (e.g., heart failure) [107]. They often consist of a combination of subject headings, free-text terms, and publication types [107]. For systematic reviews, filters are generally recommended for use instead of limits built into databases, as discussed in Item 9, because they provide the much higher sensitivity (Box 1 ) required for a comprehensive search [108].

Any filters used as part of the search strategy should be cited, whether published in a journal article or other source. This enables readers to assess the quality of the filter(s) used, as most published search filters are validated and/or peer reviewed [106, 107]. Many commonly used filters are published on the InterTASC Information Specialists' Sub-Group [109], in the Cochrane Handbook [3, 38], and through the Health Information Research Unit of McMaster University [110].

Suggested location for reporting

Cite any search filter used in the methods section, and describe adaptations made to any filter. Include the copied and pasted details of any search filter used or adapted for use as part of the full search strategy (Item 8).

\section{ITEM 11. Prior work}

Indicate when search strategies from other literature reviews were adapted or reused for a substantive part or all of the search, citing the previous review(s).

\section{Example.}

\begin{abstract}
"We included [search strategies] used in other systematic reviews for research design [111], setting [112, 113], physical activity and healthy eating [114-116], obesity [111], tobacco use prevention [117], and alcohol misuse [118]. We also used a search [strategy] for intervention (implementation strategies) that had been employed in previous Cochrane Reviews $[119,120]$, and which was originally developed based on common terms in implementation and dissemination research." [121]
\end{abstract}

\section{Explanation.}

Many authors may also examine previously published search strategies to develop the search strategies for their review. Sometimes, authors adapt or reuse these searches for different systematic reviews [122]. When basing a new search strategy on a published search strategy, it is appropriate to cite the original publication(s) consulted.

Search strategies differ from filters (Item 10) because search strategies are often developed for a specific project, not necessarily designed to be repeatedly used. Filters, on the other hand, are developed with the express purpose of reuse. Filters are often objectively derived, tested, and validated, whereas most search strategies published as part of systematic review or other evidence synthesis are "best guess," relying on the expertise of the searcher and review team [107].

As in the example above, researchers may rely on multiple prior published searches to construct a new search for a novel review. Many times, researchers will use the same searches from a published systematic review to update the existing systematic review. In either case, it is helpful to the readers to understand whether major portions of a search are being adapted or reused.

\section{Suggested location for reporting}

Report any prior work consulted, adapted, or reused in the methods section. Include the copied and pasted search strategies used, including portions or the entirety of any prior work used or adapted for use, in the full search strategy (Item 8).

\section{ITEM 12. Updates}

Report the methods used to update the search(es) (e.g., rerunning searches, email alerts).

Examples.

"Ovid Auto Alerts were set up to provide weekly updates of new literature until July 09, 2012." [123]

“Two consecutive searches were conducted and limited by publication type and by date, first from January 1, 1990, to November 30, 2012, and again from December 1, 2012, to July 31, 2015, in an updated search.... The original search strategy was used to model the updated search from December 1, 2012, to July 31, 2015. The updated search strategy was consistent with the original search; however, changes were required in the ERIC database search because of a change in the ERIC search algorithm. Excluded publication types were identical to the initial search. To improve specificity, the updated search was limited to human participants." [99]

\section{Explanation.}

The literature search is usually conducted at the initial stage of the production of a systematic review. As a consequence, the results of a search may be outdated before the review is published [124-126]. The last search in a review should be conducted ideally less than six months 
before publication [90, 92, 125]. For this reason, authors often update searches by rerunning (Box 1) the same search(es) or otherwise updating searches before the planned publication date. Updating searches differs from updating a systematic review, i.e., when the same or different authors or groups decide to redo a published systematic review to bring its findings up to date. If authors are updating a published systematic review, either authored by the same review team or another, Item 11 contains relevant guidance.

When reporting search updates, the extent of reporting depends on methods used and any changes that were made while updating the searches. If there are no changes in information sources and/or search syntax (Box $1)$, it is sufficient to indicate the date the last search was run in the methods section and in the supplementary materials. If there are any changes in information sources and/or search syntax, the changes should be indicated (e.g., different set of databases, changes in search syntax, date restrictions) in the methods section. Authors should explain why these changes were made. When there were changes in the search strategy syntax, the original and the updated searches should both be reported as described in Item 8.

If authors use email alerts or other methods to update searches, these methods can be briefly described by indicating the method used, the frequency of any updates, the name of the database(s) used, or other relevant information that will help readers understand how the authors conducted search updates. If deduplication methods are used as part of the search update process, these methods can be described using guidance in Item 16.

Suggested location for reporting

Report the methods used to update the searches in the methods section and the supplementary materials, as described above.

\section{ITEM 13. Dates of searches}

For each search strategy, provide the date when the last search occurred.

\section{Example.}

"A comprehensive literature search was initially run on 26 February 2017 and then rerun on 5 February 2018...." [127]

\section{Explanation.}

Most literature databases are regularly updated with new citations as articles are published. Citations already in the database may also be updated once new information (such as indexing terms or citing articles) is available. As an example, MEDLINE added over 900,000 indexed citations (Box 1) in fiscal year 2018 [40]. In addition, the information gathered by databases (such as author affiliations in MEDLINE) can change over time. Because new citations are regularly being added, systematic review guidelines recommend updating searches throughout the writing process to ensure that all relevant articles are retrieved [5, 92].

It is necessary for authors to document the date when searches were executed, either the date the initial search was conducted, if only searched once, or the most recent date the search was rerun. This allows readers to evaluate the currency of each search and understand what literature the search could have potentially identified [125]. In addition, it supports reproducibility and updating by allowing other researchers to use date limits to view the same "slice" of the database that the original authors used or to update a systematic review by searching from the last time point searched.

\section{Suggested location for reporting}

Report the date of the last search of the primary information sources used in the abstract for optimal clarity for readers [128]. Report the time frame during which searches were conducted, the initial search date(s), and/or the last update search date(s) in the methods section.

Report the initial and/or last update search date with each complete search strategy in the supplementary materials, as in the examples for Item 8.

\section{ITEM 14. Peer review}

Describe any search peer review process.

Example.

"The strategies were peer reviewed by another senior information specialist prior to execution using the PRESS Checklist [52]." [129]

\section{Explanation.}

Peer reviewing search strategies is an increasingly valued component of search strategy development for systematic reviews. Expert guidance recommends taking this step to help increase the robustness of the search strategy $[5,74]$. Peer reviewing (Box 1) searches is useful to help to guide and improve electronic search strategies. One of peer review's main benefits is the reduction of errors [22, 130]. Peer review may also increase the number of relevant records found for inclusion in reviews, thus improving the overall quality of the systematic review [131].

Authors should consider using the Peer Review of Electronic Search Strategies (PRESS) Guideline statement, a practice guideline for literature search peer review outlining the major components important to review and the benefits of peer reviewing searches [52]. Authors should strongly consider having the search strategy peer reviewed by an experienced searcher, information specialist, or librarian $[52,131]$. Though peer review may be conducted generally with publication of a protocol, for example, this item is designed to document search-specific peer review. 
Suggested location for reporting

Describe the use of peer review in the methods section.

\section{ITEM 15. Total records}

Document the total number of records identified from each database and other information sources.

\section{Examples.}

Methods section. "A total of 3,251 citations were retrieved from the six databases and four grey literature websites." [132]

Figure 1 PRISMA 2009 flow diagram [133]

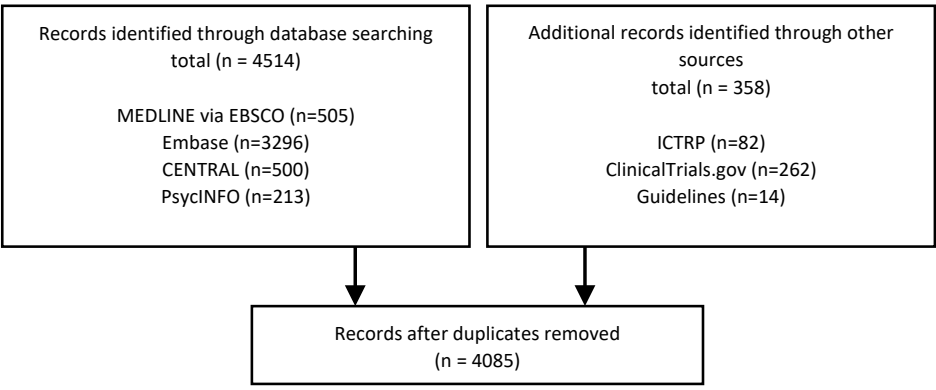

\section{Explanation.}

Recording the flow of citations through the systematic review process is a key component of the PRISMA Statement $[8,34]$. It is helpful to identify how many records (Box 1) were identified within each database and additional source. Readers can use this information to see whether databases or expert contacts constituted the majority of the records reviewed, for example. Knowing the number of records from each source also helps with reproducibility. If a reader tries to duplicate a search from a systematic review, one would expect to retrieve nearly the same results when limiting to the timeframe in the original review. If instead, the searcher locates a drastically different number of results than reported in the original review, this can be indicative of errors in the published search [22] or major changes to a database, both of which might be reasons to update a systematic review or view the systematic review's results with skepticism.

\section{Suggested location for reporting}

Report the total number of references retrieved from all sources, including updates, in the results section. Report the total number of references from each database and information source in the supplementary materials. If space permits, report the total number of references from each database in the PRISMA flow diagram [34].

\section{ITEM 16. Deduplication}

Describe the processes and any software used to deduplicate records from multiple database searches and other information sources.

Example.

“Duplicates were removed by the librarians (LP, PJE), using EndNote's duplicate identification strategy and then manually." [134]

\section{Explanation.}

Databases contain significant overlap in content. When searching in multiple databases and additional information sources, as is necessary for a systematic review, authors often employ a variety of techniques to reduce the number of duplicates within their results prior to screening [135-138]. Techniques vary in their efficacy, sensitivity, and specificity (Box 1) [136, 138]. Knowing which method is used enables readers to evaluate the process and understand to what extent these techniques may have removed false positive duplicates [138]. Authors should describe and cite any software or technique used, when applicable. If duplicates were removed manually, authors should include a description.

\section{Suggested location for reporting}

Report any deduplication method used in the methods section. The total number of references after deduplication should be reported in the PRISMA flow diagram [34].

\section{PART 4. DISCUSSION AND CONCLUSIONS}

The PRISMA-S extension is designed to be used in conjunction with PRISMA 2020 [34] and PRISMA extensions including PRISMA-P for protocols [35], PRISMA-ScR for scoping reviews [139], the PRISMA Network Meta-analyses statement [140], and PRISMA-IPD for systematic reviews using individual patient data [141]. It may also be used with other reporting guidelines that relate to systematic reviews and related review types, such as RepOrting standards for Systematic Evidence Syntheses (ROSES) [142]. It provides additional guidance for systematic review teams, information specialists, librarians, and other researchers whose work contains a literature search as a component of the research methods. Though its origins are in the biomedical fields, PRISMA-S is flexible enough to be applied in all disciplines that use methods-driven literature searching. Ultimately, PRISMA$S$ attempts to give systematic review teams a framework that helps ensure transparency and maximum reproducibility of the search component of their review.

PRISMA-S is intended to capture and provide specific guidance for reporting the most common methods used in systematic reviews today. As new methods and information sources are adopted, authors may need to 
adjust their reporting methods to accommodate new processes. Currently, PRISMA-S does not address using text mining or text analysis methods to create the search, for example, though this is an increasingly common way for information specialists to develop robust and objective search strategies [143-145]. Likewise, PRISMA-S does not require that decisions about the rationale behind choices in search terms and search construction be recorded, though this provides readers a great deal of insight. In the future, methods and rationales used to create search strategies may become more important for reproducibility.

PRISMA-S offers extensive guidance for many different types of information source and methods, many of them not described in detail in other reporting guidelines relating to literature searching. This includes detailed information on reporting study registry searches, web searches, multi-database searches, and updates. PRISMA-S can help authors report all components of their search, hopefully making the reporting process easier. As a note, PRISMA-S provides guidance on transparent reporting to authors and is not intended as a tool to either guide conduct of a systematic review or to evaluate the quality of a search or a systematic review.
The PRISMA-S checklist is available for download in Word and portable document format (PDF) formats from the PRISMA Statement website [36]. The checklist should be used together with its explanation and elaboration documentation to provide authors with guidance for the complexities of different types of information sources and methods.

We intend to work with systematic review and information specialist organizations to broadly disseminate PRISMA-S and encourage its adoption by journals. In addition, we plan to host a series of webinars discussing how to use PRISMA-S most effectively. These webinars will also be available for later viewing and will serve as a community resource.

We hope that journal editors will recommend authors of systematic reviews and other related reviews to use PRISMA-S and submit a PRISMA-S checklist with their manuscripts. We also hope that journal editors will encourage more stringent peer review of systematic review searches to ensure greater transparency and reproducibility within the review literature.

\section{BOX 1. GLOSSARY}

Browse: Browsing is the practice of scanning for information by reviewing content. This may include using tables of contents, indices in books or other materials, web directories, full journal issues, specific web pages, or other types of information scanned without using a formal search strategy.

Citation index: A type of database or database function that enables searchers to analyze relationships between publications through citations, including what publications have cited, and which publications are citing the publication(s) you are interested in. Common examples include Science Citation Index, Scopus, and Google Scholar.

Cited reference: Publication referenced in a given publication.

Citing reference: Publications that have referenced a given publication.

Database: Within PRISMA-S, this refers to a literature database designed to search journal literature. Databases may be multidisciplinary or specialized. Many include specialized search features, subject headings, and structured data designed to facilitate easy and comprehensive searching. Examples include MEDLINE, EconLit, and PsycInfo.

Digital object identifier: Also called a DOI, a digital object identifier is a unique code assigned to a publication, dataset, or other online item or collection that will remain constant over time.

Field code: Unique to each database platform and database, field codes are used to specify where a term is searched for in a database record. In PubMed, for instance, the field code [tiab] is placed after a search term to tell the database to search only within the title and abstract fields.

Filter: Filters are predefined combinations of search strategies designed to locate references meeting certain criteria, usually publication type, topic, age group, or other categorization. Filters generally are combinations of keywords, subject headings or thesaurus terms, logical operators, and database-specific syntax. Many filters are validated and offer sensitivity and specificity information that allows searchers to determine their usefulness for a given search. Filters may also be called hedges or optimal search strategies and are designed for other searchers to use and reuse.

Indexing: Application of standard terminology to a reference to describe the contents of the full article. Depending on the database or other information source, indexers may add subject headings or thesaurus terms as well as list age groups, language, human studies, study design, publication type, or other descriptive terms. Examples of indexing terminology include MEDLINE's Medical Subject Headings (MeSH) and Embase's EMTREE. 
Information source: Any database or other resource such as a website, journal table of contents, email alert, web directory, contact with authors or industry, study registry, or preprint server, etc., searched or browsed as part of the search.

Limits: Features built into databases to allow searchers to quickly restrict their search by one or more categories. Common limits built into databases include publication date ranges, language, gender, age group, and publication type. Limits are different from filters (see above) and are also not the inclusion/exclusion criteria used in the screening process.

Literature search: Here, an overall term for the entire information retrieval process as part of a systematic review. This includes the full range of searching methods and information sources, including databases, study registries, regulatory datasets, web searches, government documents, unpublished data, and much more.

Multi-database search: Many database platforms offer more than one database on the same platform. Some platforms allow users to search these multiple databases at one time; for example, using the Ovid platform to simultaneously search MEDLINE, Embase, and the Cochrane Database of Systematic Reviews.

Peer review: In PRISMA-S, this refers to the peer review of search strategies prior to executing the search. Peer review is used to identify errors, missing keywords or subject headings, and other issues within a search strategy. One commonly used tool for search strategy peer review is the Peer Review of Electronic Search Strategies (PRESS) Guideline [52].

Platform: Many databases are available on multiple different systems, each of which have their own specifications for how a search strategy can be constructed. The location or host system of the database is the platform. Platform is sometimes referred to as the interface or vendor. Common examples include Ovid, EBSCOhost, ProQuest, and Web of Science.

Records: Individual items retrieved from any type of search, though most commonly used in conjunction with database searches. Records may also be referred to as references or hits.

Repository: An online archive for varying types of electronic files, including text documents, data files, and more. Repositories may be hosted by an institution or more broadly available.

Rerun: Re-executing the same search strategy in the same database one or more times after the original search was conducted. See Updating a search strategy.

Search: Overall term for the entire information retrieval process as part of a systematic review. It can also refer to searching a specific database, website, or other information source.

Search strategy: Structure of terms, logical operators, and syntax elements (field codes [see above], adjacency operators, phrases, etc.) that is used to search a database or other information source. A search strategy may be very simple or very complex, depending on the information source and requirements of the search.

Sensitivity: A measure of how well a search strategy finds relevant articles, sensitivity (usually expressed as a percentage) is the number of relevant records found with a search strategy divided by the total number of relevant records in a given information source. Highly sensitive search strategies or filters detect most or all records that are relevant. Together with specificity, sensitivity is a measure used to assess the performance of filters. Sensitivity may also be called recall.

Specificity: A measure of how well a search strategy omits irrelevant articles, specificity (usually expressed as a percentage) is the number of irrelevant records not found with (or excluded by) a search strategy divided by the total number of irrelevant records in a given information source. Search strategies or filters with high specificity will find few irrelevant articles. Together with sensitivity, specificity is often used to assess the performance of filters.

Study registry: A database of records of research studies in progress. Originally designed for clinical trials as a location for patients to find clinical trials to join, study registries have spread beyond biomedical research to other fields. Study registries may also contain research results, posted after study completion.

Supplementary materials: Additional content for a study that does not fit in the main manuscript text. For a systematic review, supplementary materials should include full search strategies for all information sources and more complete search methods description. Supplementary materials are generally submitted with the manuscript for peer review.

Syntax: Search structure and organization, based on a set of rules governing how a search operates in a specific database and platform. Rules might include field codes, phrase and adjacency searching, Boolean operators, and truncation, amongst others.

Systematic review: For the purposes of PRISMA-S, systematic review is used for the entire family of methods-based reviews. This includes rapid reviews, scoping reviews, meta-narrative reviews, realist reviews, meta-ethnography, and more. 
Updating a search strategy: To ensure currency, authors often search for additional information throughout the systematic review process or before submitting a report. The search may be updated by running the exact same search (rerunning the search) or by conducting a new or modified search to locate additional references.

\section{BOX 2. SUPPLEMENTARY MATERIALS}

Fully documenting a search will require publication of supplementary materials. Due to the instability of supplementary materials published as part of a journal article, uploading complete documentation to a secure and permanent archive is recommended.

\section{Options for secure and permanent archives}

Many options exist for uploading documentation. Ideally, use an archive or repository that will provide a digital object identifier (DOI) for any uploaded materials (Box 1). These are a few of the many options available.

Institutional repository: Many institutions or their affiliated libraries host online repository systems for their faculty, staff, and students. An example is the University of Michigan's Deep Blue Data system (https://deepblue.lib.umich.edu/).

Open Science Framework (http://osf.io/): The Open Science Framework (OSF) platform enables the storage of any documentation associated with a research study. It is possible to create DOIs for individual files or groups of files. OSF is openly and freely available.

figshare (https:/ / figshare.com/): figshare is a commercial platform that allows researchers to share any type of data or research output. It is possible to create DOIs for individual files or collections.

Zenodo (https://zenodo.org/): Zenodo is a general purpose, freely available open access repository available from CERN for research data and associated materials. Uploaded materials are assigned DOIs.

What documentation to upload

Materials related to all PRISMA-S checklist items can be included in supplementary materials. Sufficient information should be uploaded that would enable an interested reader to replicate the search strategy. Specifically, it is recommended that documentation relating to the full search strategies for all information sources and methods be included in supplementary materials.

Optionally, authors may wish to upload additional supplementary information, including files of all references retrieved, all references after deduplication, and all references to included studies. Authors who wish to share these files should note that abstracts are copyrighted materials and should be removed from files before sharing them publicly.

For an example of supplementary materials related to a systematic review search, see:

MacEachern M. Literature search strategies for “Substance Use Education in Schools of Nursing: A Systematic Review of the Literature" [Data set]. University of Michigan - Deep Blue; 2017. DOI: http://dx.doi.org/10.7302/Z24X560Q.

In this example, the materials shared include a Read Me file to explain the files, EndNote (.enlx) files of screened references, the original files imported into EndNote, and the complete, reproducible search strategies for all information sources.

\section{LIST OF ABBREVIATIONS}

DOI: digital object identifier

PRESS: Peer Review of Electronic Search Strategies

PRISMA: Preferred Reporting Items for Systematic reviews and Meta-Analyses

PRISMA-IPD: PRISMA for individual patient data

PRISMA-P: PRISMA for systematic review protocols

PRISMA-ScR: PRISMA for scoping reviews

ROSES: RepOrting standards for Systematic Evidence Syntheses 


\section{DECLARATIONS}

\section{Ethics approval and consent to participate}

This study was declared exempt by the University of Utah Institutional Review Board (IRB_00088425). Consent was received from all survey participants.

\section{Consent for publication}

Not applicable.

\section{Availability of data and materials}

All data are available via the PRISMA-S PRISMA Search Reporting Extension OSF site (http://dx.doi.org/10.17605/OSF.IO/YGN9W) [31]. This includes all data relating to item development, survey instruments, data from the Delphi surveys, consent documents, and data appendixes (directly available at: https://osf.io/79dvh/).

\section{Competing interests}

The authors declare no competing interests. Matthew J. Page and David Moher are leading the PRISMA 2020 update.

\section{Funding statements}

Melissa L. Rethlefsen was funded in part by the University of Utah's Center for Clinical and Translational Science under the National Center for Advancing Translational Sciences of the National Institutes of Health Award Number UL1TR002538 in 2017-2018. The content is solely the responsibility of the authors and does not necessarily represent the official views of the National Institutes of Health.

Shona Kirtley was funded by Cancer Research UK (grant C49297/ A27294). The funder had no role in study design, data collection and analysis, decision to publish, or preparation of the manuscript. The views expressed are those of the authors and not necessarily those of Cancer Research UK.

Matthew J. Page is supported by an Australian Research Council Discovery Early Career Researcher Award (DE200101618).

David Moher is supported by a University Research Chair, University of Ottawa, Ottawa, Canada.

The consensus conference was sponsored by the Systematic Reviews Special Interest Group (SIG) of the Medical Library Association. There was no specific funding associated with this event.

\section{Authors' contributions}

Melissa L. Rethlefsen conceived and designed the study, conducted the thematic and quantitative analyses, curated the data, drafted the manuscript, and reviewed and edited the manuscript. Rethlefsen is the guarantor. Jonathan B. Koffel and Shona Kirtley contributed to the design of the study, developed the literature search strategies, contributed to the thematic content analyses, drafted a portion of the elaboration and explanation, and reviewed and edited the manuscript. Koffel developed the survey instrument. Rethlefsen, Koffel, and Kirtley hosted and organized the consensus conference. Siw Waffenschmidt and Ana Patricia Ayala contributed to the thematic content analysis, drafted a portion of the Explanation and Elaboration, and reviewed and edited the manuscript. Waffenschmidt supervised the draft revision documentation. David Moher helped conceive and design the study. Matthew J. Page provided substantive review and editing of the checklist, Explanation and Elaboration, and final manuscript.

\section{ACKNOWLEDGMENTS}

We would like to thank all of the members of the PRISMA-S Group, which is comprised of participants in the Delphi process, consensus conference, or both. PRISMA-S Group members include Heather Blunt (Dartmouth College), Tara Brigham, AHIP (Mayo Clinic in Florida), Steven Chang (La Trobe University), Justin Clark (Bond University), Aislinn Conway (BORN Ontario and CHEO Research Institute), Rachel Couban, AHIP (McMaster University), Shelley de Kock (Kleijnen Systematic Reviews Ltd), Kelly Farrah, AHIP (Canadian Agency for Drugs and Technologies in Health [CADTH]), Paul Fehrmann (Kent State University), Margaret Foster, AHIP (Texas A\&M University), Susan A. Fowler (Washington University in St. Louis), Julie Glanville (University of York), Elizabeth Harris (La Trobe University), Lilian Hoffecker (University of Colorado Denver), Jaana Isojarvi (Tampere University), David Kaunelis (CADTH), Hans Ket (VU Amsterdam), Paul Levay (National Institute for Health and Care Excellence [NICE]), Jennifer Lyon, AHIP, Jessie McGowan, AHIP (uOttawa), M. Hassan Murad (Mayo Clinic), Joey Nicholson (NYU Langone Health), Virginia Pannabecker, AHIP (Virginia Tech), Robin Paynter (VA Portland Health Care System), Rachel Pinotti, AHIP (Icahn School of Medicine at Mount Sinai), Amanda Ross-White, AHIP (Queens University), Margaret Sampson, AHIP (CHEO), Tracy Shields, AHIP (Naval Medical Center Portsmouth), Adrienne Stevens (Ottawa Hospital Research Institute), Anthea Sutton (University of Sheffield), Elizabeth Weinfurter (University of Minnesota), Kath Wright (University of York), and Sarah Young (Carnegie Mellon University). We'd also like to thank Kate Nyhan (Yale University), Katharina Gronostay (IQWiG), the many others who contributed to the PRISMA-S project anonymously or as draft reviewers, and our peer reviewers. We'd like to give special thanks to the late Douglas G. Altman (University of Oxford) for his support 
and guidance, and the cochairs of the Medical Library Association's Systematic Reviews SIG in 2016, Margaret Foster (Texas A\&M University) and Susan Fowler (Washington University in St. Louis), for allowing us to use one of their meeting times for the consensus conference.

\section{REFERENCES}

1. Lefebvre C, Glanville J, Briscoe S, Littlewood A, Marshall C, Metzendorf MI, Noel-Storr A, Rader T, Shokraneh F, Thomas J, Wieland L. Searching for and selecting studies. In: Higgins J, Thomas J, Chandler J, Cumpston M, Li T, Page M, Welch V, eds. Cochrane handbook for systematic reviews of interventions. Version 6.0. Cochrane; 2019.

2. Centre for Reviews and Dissemination. Systematic reviews: CRD's guidance for undertaking reviews in health care. 1.3 Undertaking the review [Internet]. The Centre, University of York; 2009 [cited 31 Jan 2020].

<https://www.york.ac.uk/media/crd/Systematic_Reviews .pdf>.

3. Lefebvre C, Glanville J, Briscoe S, Littlewood A, Marshall C, Metzendorf MI. Technical supplement to chapter 4: searching for and selecting studies. In: Higgins JPT, Thomas J, Chandler J, Cumpston M, Li T, Page MJ, eds. Cochrane handbook for systematic reviews of interventions. Version 6.0: Cochrane; 2019.

4. Relevo R, Balshem H. Finding evidence for comparing medical interventions: AHRQ and the Effective Health Care Program. J Clin Epidemiol. 2011 Nov;64(11):1168-77. DOI: http://dx.doi.org/10.1016/j.jclinepi.2010.11.022.

5. Institute of Medicine (US), Committee on Standards for Systematic Reviews of Comparative Effectiveness Research, Eden J. Finding what works in health care: standards for systematic reviews. Washington, DC: National Academies Press; 2011.

6. European Network for Health Technology Assessment (EUnetHTA). Process of information retrieval for systematic reviews and health technology assessments on clinical effectiveness: guideline; version 2.0 [Internet]. Diemen, The Netherlands: EUnetHTA; 2019 [cited 31 Jan 2020].

<https:/ / eunethta.eu/wpcontent/uploads/2020/01/EUnetHTA_Guideline_Informati on_Retrieval_v2-0.pdf>.

7. Sampson M, McGowan J, Tetzlaff J, Cogo E, Moher D. No consensus exists on search reporting methods for systematic reviews. J Clin Epidemiol. 2008 Aug;61(8):748-54. DOI:

http://dx.doi.org/10.1016/i.jclinepi.2007.10.009.

8. Liberati A, Altman DG, Tetzlaff J, Mulrow C, Gotzsche PC, Ioannidis JP, Clarke M, Devereaux PJ, Kleijnen J, Moher D.

The PRISMA statement for reporting systematic reviews and meta-analyses of studies that evaluate health care interventions: explanation and elaboration. PLoS Med. 2009 Jul 21;6(7):e1000100. DOI:

http://dx.doi.org/10.1371/journal.pmed.1000100.

9. Page MJ, Moher D. Evaluations of the uptake and impact of the Preferred Reporting Items for Systematic reviews and Meta-Analyses (PRISMA) Statement and extensions: a scoping review. Syst Rev. 2017;6(1):263. DOI: http://dx.doi.org/10.1186/s13643-017-0663-8.

10. Koffel JB, Rethlefsen ML. Reproducibility of search strategies is poor in systematic reviews published in high-impact pediatrics, cardiology and surgery journals: a cross-sectional study. PLoS One. 2016;11(9):e0163309. DOI: http://dx.doi.org/10.1371/journal.pone.0163309.

11. Faggion CM Jr., Wu YC, Tu YK, Wasiak J. Quality of search strategies reported in systematic reviews published in stereotactic radiosurgery. Br J Radiol. 2016 Jun;89(1062):20150878. DOI: http://dx.doi.org/10.1259/bjr.20150878.

12. Layton D. A critical review of search strategies used in recent systematic reviews published in selected prosthodontic and implant-related journals: are systematic reviews actually systematic? Int J Prosthodont. 2017

Jan/Feb;30(1):13-21. DOI:

http://dx.doi.org/10.11607/ijp.5193.

13. Yaylali IE, Alacam T. Critical assessment of search strategies in systematic reviews in endodontics. J Endod. 2016 Jun;42(6):854-60. DOI: http://dx.doi.org/10.1016/i.joen.2016.02.018.

14. Page MJ, Shamseer L, Altman DG, Tetzlaff J, Sampson M, Tricco AC, Catalá-López F, Li L, Reid EK, Sarkis-Onofre R, Moher D. Epidemiology and reporting characteristics of systematic reviews of biomedical research: a cross-sectional study. PLoS Med. 2016;13(5):e1002028-e. DOI: http://dx.doi.org/10.1371/journal.pmed.1002028.

15. Koffel JB. Use of recommended search strategies in systematic reviews and the impact of librarian involvement: a cross-sectional survey of recent authors. PLoS One. 
2015;10(5):e0125931. DOI:

http://dx.doi.org/10.1371/journal.pone.0125931.

16. Rethlefsen ML, Farrell AM, Osterhaus Trzasko LC, Brigham TJ. Librarian co-authors correlated with higher quality reported search strategies in general internal medicine systematic reviews. J Clin Epidemiol. 2015 Jun;68(6):617-26. DOI: http://dx.doi.org/10.1016/j.jclinepi.2014.11.025.

17. Meert D, Torabi N, Costella J. Impact of librarians on reporting of the literature searching component of pediatric systematic reviews. J Med Libr Assoc. 2016 Oct;104(4):26777. DOI: http://dx.doi.org/10.3163/1536-5050.104.4.004.

18. Maggio LA, Tannery NH, Kanter SL. Reproducibility of literature search reporting in medical education reviews. Acad Med. 2011;86(8):1049-54. DOI: http://dx.doi.org/10.1097/ ACM.0b013e31822221e7.

19. Yoshii A, Plaut DA, McGraw KA, Anderson MJ, Wellik KE. Analysis of the reporting of search strategies in Cochrane systematic reviews. J Med Libr Assoc. 2009 Jan;97(1):21-9. DOI: http:/ / dx.doi.org/10.3163/1536-5050.97.1.004.

20. Franco JVA, Garrote VL, Escobar Liquitay CM, Vietto V. Identification of problems in search strategies in Cochrane reviews. Res Synth Methods. 2018;9(3):408-16. DOI: http://dx.doi.org/10.1002/jrsm.1302.

21. Salvador-Oliván JA, Marco-Cuenca G, Arquero-Avilés R. Errors in search strategies used in systematic reviews and their effects on information retrieval. J Med Libr Assoc. 2019 Apr;107(2):210-21. DOI: http://dx.doi.org/10.5195/jmla.2019.567.

22. Sampson M, McGowan J. Errors in search strategies were identified by type and frequency. J Clin Epidemiol. 2006 Oct;59(10):1057-63. DOI: http://dx.doi.org/10.1016/j.jclinepi.2006.01.007.

23. Mullins MM, DeLuca JB, Crepaz N, Lyles CM. Reporting quality of search methods in systematic reviews of HIV behavioral interventions (2000-2010): are the searches clearly explained, systematic and reproducible? Res Synth Methods. 2014;5(2):116-30. DOI: http:// dx.doi.org/10.1002/jrsm.1098.

24. Rader T, Mann M, Stansfield C, Cooper C, Sampson M. Methods for documenting systematic review searches: a discussion of common issues. Res Synth Methods. 2014 Jun;5(2):98-115. DOI: http:// dx.doi.org/10.1002/jrsm.1097.

25. Briscoe $\mathrm{S}$. Web searching for systematic reviews: a case study of reporting standards in the UK Health Technology
Assessment programme. BMC Res Notes. 2015 Apr 16;8:153. DOI: http://dx.doi.org/10.1186/s13104-015-1079-y.

26. Moher D, Stewart L, Shekelle P. All in the family: systematic reviews, rapid reviews, scoping reviews, realist reviews, and more. Syst Rev. 2015 Dec 22;4:183. DOI:

http://dx.doi.org/10.1186/s13643-015-0163-7.

27. Grant MJ, Booth A. A typology of reviews: an analysis of 14 review types and associated methodologies. Health Inf Libr J. 2009 Jun;26(2):91-108. DOI: http://dx.doi.org/10.1111/j.1471-1842.2009.00848.x.

28. Rethlefsen ML, Koffel JB, Kirtley S. PRISMA-Search (PRISMA-S) extension to PRISMA development protocol [Internet]. Equator Network; 2016 [cited 16 Jan 2020].

<https://www.equator-network.org/wpcontent/uploads/2009/02/Protocol-PRISMA-SDelphi.pdf>.

29. Moher D, Schulz KF, Simera I, Altman DG. Guidance for developers of health research reporting guidelines. PLoS Med. 2010;7(2):e1000217-e. DOI:

http://dx.doi.org/10.1371/journal.pmed.1000217.

30. Hsu C, Sandford BA. The Delphi technique: making sense of consensus. Pract Assess Res Eval [Internet]. 2007;12(10).

(Available from:

< https://scholarworks.umass.edu/cgi/viewcontent.cgi?arti

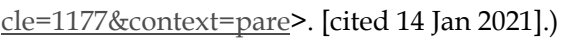

31. Rethlefsen ML, Koffel JB, Kirtley S, Ayala AP, Waffenschmidt S. PRISMA-S: PRISMA search reporting extension [Internet]. Open Science Framework; 2019. DOI: http://dx.doi.org/10.17605/OSF.IO/YGN9W.

32. Hypothesis [Internet]. Hypothesis Project; 2020 [cited 3 Jan 2020]. <https:// web.hypothes.is/>.

33. Page MJ, McKenzie JE, Bossuyt PM, Boutron I, Hoffmann T, Mulrow C, Shamseer L, Moher D. Updating the PRISMA reporting guideline for systematic reviews and metaanalyses: study protocol [Internet]. 2018 [cited 13 Feb 2020]. $<$ http://osf.io/2v7mk>.

34. Page MJ, McKenzie JE, Bossuyt PM, Boutron I, Hoffmann T, Mulrow C, Shamseer L, Tetzlaff J, Akl EA, Brennan S, Chou R, Glanville J, Grimshaw J, Hróbjartsson A, Lalu M, Li T, Loder E, Mayo-Wilson E, McDonald S, McGuinness L, Stewart L, Thomas J, Tricco AC, Welch VA, Whiting P, Moher D. The PRISMA 2020 statement: an updated guideline for reporting systematic reviews [Internet]. 
MetaArXiv Preprints; 2020. DOI:

http://dx.doi.org/10.31222/osf.io/v7gm2.

35. Shamseer L, Moher D, Clarke M, Ghersi D, Liberati A, Petticrew M, Shekelle P, Stewart LA; PRISMA-P Group. Preferred reporting items for systematic review and metaanalysis protocols (PRISMA-P) 2015: elaboration and explanation. BMJ. 2015 Jan 2;350:g7647. DOI: http://dx.doi.org/10.1136/bmj.g7647.

36. PRISMA. Transparent reporting of systematic reviews and meta-analyses [Internet]. Ottawa Hospital Research Institute and University of Oxford; 2015 [cited 13 Feb 2020].

<http:// prisma-statement.org/>.

37. Schneider KJ, Leddy JJ, Guskiewicz KM, Seifert T, McCrea $\mathrm{M}$, Silverberg ND, Feddermann-Demont N, Iverson GL, Hayden A, Makdissi M. Rest and treatment/rehabilitation following sport-related concussion: a systematic review. Br J Sports Med. 2017 Jun;51(12):930-4. DOI: http:/ / dx.doi.org/10.1136/bjsports-2016-097475.

38. Lefebvre C, Manheimer E, Glanville J. Searching for studies [Internet]. Cochrane; 2011 [cited 25 Nov 2014].

<http://handbook.cochrane.org/chapter_6/6_searching_for studies.htm>.

39. Bramer WM, Rethlefsen ML, Kleijnen J, Franco OH. Optimal database combinations for literature searches in systematic reviews: a prospective exploratory study. Syst Rev. 2017 Dec 6;6(1):245. DOI: http://dx.doi.org/10.1186/s13643-017-0644y.

40. National Library of Medicine. MEDLINE®: description of the database [Internet]. Bethesda, MD: The Library; 2019 [cited 1 Feb 2020]. <https://www.nlm.nih.gov/bsd/medline.html>.

41. Elsevier. Embase content [Internet]. Elsevier; 2019 [cited 28 Feb 2019]. <https://www.elsevier.com/solutions/embasebiomedical-research/embase-coverage-and-content>.

42. Elsevier. Scopus [Internet]. Elsevier; 2020 [cited 1 Feb 2020]. $<$ http://www.scopus.com>.

43. American Psychological Association. PsycInfo [Internet]. The Association; 2020 [cited 1 Feb 2020]. <https://www.apa.org/pubs/databases/psycinfo>.

44. American Economic Association. EconLit [Internet]. The Association; 2020 [cited 1 Feb 2020]. <https://www.aeaweb.org/econlit/>.
45. BIREME, PAHO, WHO, Latin American and Caribbean Center on Health Sciences Information. LILACS [Internet]. Sao Paolo, Brazil: The Center; 2020 [cited 1 Feb 2020]. $<$ http://lilacs.bvsalud.org/en/>.

46. World Health Organization. African index medicus [Internet]. Brazzaville, Congo: The Organization; 2020 [cited 14 Jan 2021]. <https://indexmedicus.afro.who.int/>.

47. Craven J, Jefferies J, Kendrick J, Nicholls D, Boynton J, Frankish R. A comparison of searching the Cochrane library databases via CRD, Ovid and Wiley: implications for systematic searching and information services. Health Inf Libr J. 2014 Mar;31(1):54-63. DOI: http://dx.doi.org/10.1111/hir.12046.

48. Bramer WM, Giustini D, Kleijnen J, Franco OH. Searching Embase and MEDLINE by using only major descriptors or title and abstract fields: a prospective exploratory study. Syst Rev. 2018 Nov 20;7(1):200. DOI: http://dx.doi.org/10.1186/s13643-018-0864-9.

49. Younger $\mathrm{P}$, Boddy $\mathrm{K}$. When is a search not a search? a comparison of searching the AMED complementary health database via EBSCOhost, OVID and DIALOG. Health Inf Libr J. 2009 Jun;26(2):126-35. DOI: http://dx.doi.org/10.1111/j.1471-1842.2008.00785.x.

50. Fraser C, Murray A, Burr J. Identifying observational studies of surgical interventions in MEDLINE and EMBASE. BMC Med Res Methodol. 2006 Aug 18;6:41. DOI: http://dx.doi.org/10.1186/1471-2288-6-41.

51. De Cagna F, Fusar-Poli L, Damiani S, Rocchetti M, Giovanna G, Mori A, Politi P, Brondino N. The role of intranasal oxytocin in anxiety and depressive disorders: a systematic review of randomized controlled trials. Clin Psychopharmacol Neurosci. 2019 Feb 28;17(1):1-11. DOI: http://dx.doi.org/10.9758/cpn.2019.17.1.1.

52. McGowan J, Sampson M, Salzwedel DM, Cogo E, Foerster V, Lefebvre C. PRESS Peer Review of Electronic Search Strategies: 2015 guideline statement. J Clin Epidemiol. 2016 Jul;75:40-6. DOI: http://dx.doi.org/10.1016/i.jclinepi.2016.01.021.

53. Rutjes AW, Juni P, da Costa BR, Trelle S, Nuesch E, Reichenbach S. Viscosupplementation for osteoarthritis of the knee: a systematic review and meta-analysis. Ann Intern Med. 2012 Aug 7;157(3):180-91. DOI: 
http:/ / dx.doi.org/10.7326/0003-4819-157-3-201208070$\underline{00473 .}$

54. Potthast R, Vervolgyi V, McGauran N, Kerekes MF, Wieseler B, Kaiser T. Impact of inclusion of industry trial results registries as an information source for systematic reviews. PLoS One. 2014;9(4):e92067. DOI: http://dx.doi.org/10.1371/journal.pone.0092067.

55. Turner EH, Matthews AM, Linardatos E, Tell RA, Rosenthal R. Selective publication of antidepressant trials and its influence on apparent efficacy. N Engl J Med. 2008 Jan 17;358(3):252-60. DOI: http://dx.doi.org/10.1056/NEJMsa065779.

56. Baudard M, Yavchitz A, Ravaud P, Perrodeau E, Boutron I. Impact of searching clinical trial registries in systematic reviews of pharmaceutical treatments: methodological systematic review and reanalysis of meta-analyses. BMJ. 2017 Feb 17;356:j448. DOI: http://dx.doi.org/10.1136/bmj.j448.

57. Zarin DA, Tse T, Williams RJ, Carr S. Trial reporting in ClinicalTrials.gov - the final rule. N Engl J Med. 2016 Nov 17;375(20):1998-2004. DOI: http://dx.doi.org/10.1056/NEJMsr1611785.

58. Anderson ML, Chiswell K, Peterson ED, Tasneem A, Topping J, Califf RM. Compliance with results reporting at ClinicalTrials.gov. N Engl J Med. 2015 Mar 12;372(11):10319. DOI: http:/ / dx.doi.org/10.1056/NEJMsa1409364.

59. DeVito NJ, Bacon S, Goldacre B. Compliance with legal requirement to report clinical trial results on ClinicalTrials.gov: a cohort study. Lancet. 2020 Jan 17;395(10221):361-9. DOI: http://dx.doi.org/10.1016/S01406736(19)33220-9.

60. Stockdale J, Cassell J, Ford E. "Giving something back": a systematic review and ethical enquiry into public views on the use of patient data for research in the United Kingdom and the Republic of Ireland. Wellcome Open Res. 2018;3:6. DOI: http:/ / dx.doi.org/10.12688/wellcomeopenres.13531.2.

61. Mascarenhas M, Garasia S, Berthiaume P, Corrin T, Greig J, Ng V, Young I, Waddell L. A scoping review of published literature on chikungunya virus. PLoS One. 2018;13(11):e0207554. DOI: http://dx.doi.org/10.1371/journal.pone.0207554.

62. Gates M, Wingert A, Featherstone R, Samuels C, Simon C, Dyson MP. Impact of fatigue and insufficient sleep on physician and patient outcomes: a systematic review. BMJ Open. 2018 Sep 21;8(9):e021967. DOI: http://dx.doi.org/10.1136/bmjopen-2018-021967.

63. Song F, Parekh-Bhurke S, Hooper L, Loke YK, Ryder JJ, Sutton AJ, Hing CB, Harvey I. Extent of publication bias in different categories of research cohorts: a meta-analysis of empirical studies. BMC Med Res Methodol. 2009 Nov 26;9:79. DOI: http://dx.doi.org/10.1186/1471-2288-9-79.

64. Egger M, Zellweger-Zahner T, Schneider M, Junker C, Lengeler C, Antes G. Language bias in randomised controlled trials published in English and German. Lancet. 1997 Aug 2;350(9074):326-9. DOI: http://dx.doi.org/10.1016/S0140-6736(97)02419-7.

65. Stansfield C, Dickson K, Bangpan M. Exploring issues in the conduct of website searching and other online sources for systematic reviews: how can we be systematic? Syst Rev. 2016 Nov 15;5(1):191. DOI: http://dx.doi.org/10.1186/s13643-016-0371-9.

66. Farrah K, Mierzwinski-Urban M. Almost half of references in reports on new and emerging nondrug health technologies are grey literature. J Med Libr Assoc. 2019 Jan;107(1):43-8. DOI: http://dx.doi.org/10.5195/jmla.2019.539.

67. Piasecki J, Waligora M, Dranseika V. Google search as an additional source in systematic reviews. Sci Eng Ethics. 2018 Apr;24(2):809-10. DOI: http://dx.doi.org/10.1007/s11948017-0010-4.

68. Dax the duck. Measuring the "filter bubble": how Google is influencing what you click. DuckDuckGo Blog [Internet]. 2018 [cited 6 Jan 2021]. <https://spreadprivacy.com/googlefilter-bubble-study/>.

69. Scherer RW, Meerpohl JJ, Pfeifer N, Schmucker C, Schwarzer G, von Elm E. Full publication of results initially presented in abstracts. Cochrane Database Syst Rev. 2018 Nov 20;11:MR000005. DOI: http://dx.doi.org/10.1002/14651858.MR000005.pub4.

70. McAuley L, Pham B, Tugwell P, Moher D. Does the inclusion of grey literature influence estimates of intervention effectiveness reported in meta-analyses? Lancet. 2000 Oct 7;356(9237):1228-31. DOI: http:/ / dx.doi.org/10.1016/S0140-6736(00)02786-0. 
71. ProceedingsFirst [Internet]. OCLC; 2018 [cited 28 Feb 2019]. $<$ https://help.oclc.org/Discovery_and_Reference/FirstSear ch/FirstSearch_databases/ProceedingsFirst>.

72. Directory of published papers [Internet]. InterDok Media Services; 2019 [cited 15 Jan 2021]. <http://www.interdok.com/search_paper.php $>$.

73. International AIDS Society. Abstract archive [Internet]. The Society; 2019 [cited 6 Jan 2021]. <http:// www.abstractarchive.org/>.

74. Foster MJ, Jewell ST, eds. Assembling the pieces of a systematic review: guide for librarians. Medical Library Association Books Series. Lanham, MD: Rowman \& Littlefield; 2017.

75. Stephens RJ, Dettmer MR, Roberts BW, Ablordeppey E, Fowler SA, Kollef MH, Fuller BM. Practice patterns and outcomes associated with early sedation depth in mechanically ventilated patients: a systematic review and meta-analysis. Crit Care Med. 2018 Mar;46(3):471-9. DOI: http://dx.doi.org/10.1097/CCM.0000000000002885.

76. Kunneman M, Gionfriddo MR, Toloza FJK, Gartner FR, Spencer-Bonilla G, Hargraves IG, Erwin PJ, Montori VM. Humanistic communication in the evaluation of shared decision making: a systematic review. Patient Educ Couns. 2018 Nov 12;102(3):452-66. DOI:

http://dx.doi.org/10.1016/i.pec.2018.11.003.

77. Spurling GK, Del Mar CB, Dooley L, Foxlee R, Farley R. Delayed antibiotic prescriptions for respiratory infections. Cochrane Database Syst Rev. 2017 Sep 7;9:CD004417. DOI: http:/ / dx.doi.org/10.1002/14651858.CD004417.pub5.

78. Wright K, Golder S, Rodriguez-Lopez R. Citation searching: a systematic review case study of multiple risk behaviour interventions. BMC Med Res Methodol. 2014 Jun 3;14:73. DOI: http://dx.doi.org/10.1186/1471-2288-14-73.

79. Zarychanski R, Turgeon AF, McIntyre L, Fergusson DA Erythropoietin-receptor agonists in critically ill patients: a meta-analysis of randomized controlled trials. CMAJ. 2007 Sep 25;177(7):725-34. DOI: http://dx.doi.org/10.1503/cmaj.071055.

80. Degenhardt L, Peacock A, Colledge S, Leung J, Grebely J, Vickerman P, Stone J, Cunningham EB, Trickey A, Dumchev K, Lynskey M, Griffiths P, Mattick RP, Hickman M, Larney S. Global prevalence of injecting drug use and sociodemographic characteristics and prevalence of HIV,
$\mathrm{HBV}$, and $\mathrm{HCV}$ in people who inject drugs: a multistage systematic review. Lancet Glob Health. 2017

Dec;5(12):e1192-e207. DOI:

http://dx.doi.org/10.1016/S2214-109X(17)30375-3.

81. Kirkham JJ, Dwan KM, Altman DG, Gamble C, Dodd S, Smyth R, Williamson PR. The impact of outcome reporting bias in randomised controlled trials on a cohort of systematic reviews. BMJ. 2010 Feb 15;340:c365. DOI:

http://dx.doi.org/10.1136/bmj.c365.

82. Hodkinson A, Dietz KC, Lefebvre C, Golder S, Jones M, Doshi P, Heneghan C, Jefferson T, Boutron I, Stewart L. The use of clinical study reports to enhance the quality of systematic reviews: a survey of systematic review authors. Syst Rev. 2018 Aug 8;7(1):117. DOI: http:/ / dx.doi.org/10.1186/s13643-018-0766-x.

83. Musini VM, Lawrence KA, Fortin PM, Bassett K, Wright JM. Blood pressure lowering efficacy of renin inhibitors for primary hypertension. Cochrane Database Syst Rev. 2017 Apr 5;4:CD007066. DOI: http://dx.doi.org/10.1002/14651858.CD007066.pub3.

84. Samarasekera N, Smith C, Al-Shahi Salman R. The association between cerebral amyloid angiopathy and intracerebral haemorrhage: systematic review and metaanalysis. J Neurol Neurosurg Psychiatry. 2012 Mar;83(3):275-81. DOI: http:// dx.doi.org/10.1136/jnnp2011-300371.

85. Tham T, Machado R, Khaymovich J, Costantino P. Detection of HPV16, HPV18, p16, and E6/E7 MRNA in nasopharyngeal cancer: a systematic review and metaanalysis [Internet]. bioRXiv; 2018 [cited 6 Jan 2021]. <https://www.biorxiv.org/content/biorxiv/early/2018/08 /27/401554.full.pdf>

86. Lin J, Wilbur WJ. PubMed related articles: a probabilistic topic-based model for content similarity. BMC Bioinformatics. 2007 Oct 30;8:423. DOI: http://dx.doi.org/10.1186/1471-2105-8-423.

87. Clarivate Analytics. Web of Science core collection help: Related records [Internet]. Clarivate Analytics; 2018 [cited 1 Feb 2020].

$<\underline{\text { https://images.webofknowledge.com/images/help/WOS }}$ /hp_related_records.html>.

88. Bennett KG, Berlin NL, MacEachern MP, Buchman SR, Preminger BA, Vercler CJ. The ethical and professional use 
of social media in surgery: a systematic review of the literature. Plast Reconstr Surg. 2018 Sep;142(3):388e-98e. DOI: http://dx.doi.org/10.1097/PRS.0000000000004692.

89. Varley-Campbell J, Cooper C, Wilkerson D, Wardle S, Greeves J, Lorenc T. Sex-specific changes in physical performance following military training: a systematic review. Sports Med. 2018 Nov;48(11):2623-40. DOI: http://dx.doi.org/10.1007/s40279-018-0983-4.

90. Chandler J, Churchill R, Higgins J, Lasserson T, Tovey D. Methodological standards for the conduct of new Cochrane Intervention Reviews: version 2.1 [Internet]. 2011 [cited 1 Feb 2020]. <https://sti.cochrane.org/sites/sti.cochrane.org/files/publi c/uploads/Methodological\%20standards $\% 20$ for $\% 20$ the $\% 20$ conduct $\% 20$ of $\% 20$ Cochrane $\% 20$ Intervention $\% 20$ Reviews.PD F>.

91. Canadian Agency on Drugs and Technology in Health. Grey matters: a practical tool for searching health-related grey literature [Internet]. Ottawa, ON, Canada: The Agency; 2019 [cited 1 Feb 2020].

<https://www.cadth.ca/resources/finding-evidence/greymatters $>$.

92. Higgins J, Lasserson T, Chandler J, Tovey D, Churchill R. Methodological expectations of Cochrane intervention reviews [Internet]. London, UK: Cochrane; 2019 [cited 3 Jan 2020]. <https://community.cochrane.org/mecir-manual>.

93. Kim Y. Fostering scientists' data sharing behaviors via data repositories, journal supplements, and personal communication methods. Inform Process Manag. 2017 Jul;53(4):871-85. DOI: http://dx.doi.org/10.1016/j.ipm.2017.03.003.

94. National Center for Biotechnology Information. PubMed Central [Internet]. Bethesda, MD: National Library of Medicine; 2021 [cited 9 Jan 2020]. <https://www.ncbi.nlm.nih.gov/pmc/>.

95. Thomas LH, Coupe J, Cross LD, Tan AL, Watkins CL. Interventions for treating urinary incontinence after stroke in adults. Cochrane Database Syst Rev. 2019 Feb 1;2:CD004462. DOI: http://dx.doi.org/10.1002/14651858.CD004462.pub4.

96. Speer K, Upton D, Semple S, McKune A. Systemic low-grade inflammation in post-traumatic stress disorder: a systematic review. J Inflamm Res. 2018;11:111-21. DOI: http://dx.doi.org/10.2147/JIR.S155903.
97. Rudmik L, Soler ZM. Medical therapies for adult chronic sinusitis: a systematic review. JAMA. 2015 Sep 1;314(9):92639. DOI: $\underline{\text { http:// dx.doi.org/10.1001/jama.2015.7544. }}$.

98. Joseph MS, Tincopa MA, Walden P, Jackson E, Conte ML, Rubenfire M. The impact of structured exercise programs on metabolic syndrome and its components: a systematic review. Diabetes Metab Syndr Obes. 2019;12:2395-404. DOI: http://dx.doi.org/10.2147/DMSO.S211776.

99. Lumba-Brown A, Yeates KO, Sarmiento K, Breiding MJ, Haegerich TM, Gioia GA, Turner M, Benzel EC, Suskauer SJ, Giza CC, Joseph M, Broomand C, Weissman B, Gordon W, Wright DW, Moser RS, McAvoy K, Ewing-Cobbs L, Duhaime AC, Putukian M, Holshouser B, Paulk D, Wade SL, Herring SA, Halstead M, Keenan HT, Choe M, Christian CW, Guskiewicz K, Raksin PB, Gregory A, Mucha A, Taylor HG, Callahan JM, DeWitt J, Collins MW, Kirkwood MW, Ragheb J, Ellenbogen RG, Spinks TJ, Ganiats TG, Sabelhaus LJ, Altenhofen K, Hoffman R, Getchius T, Gronseth G, Donnell Z, O'Connor RE, Timmons SD. Diagnosis and management of mild traumatic brain injury in children: a systematic review. JAMA Pediatr. 2018 Nov 1;172(11):e182847. DOI: http://dx.doi.org/10.1001/jamapediatrics.2018.2847.

100. Kugley S, Wade A, Thomas J, Mahood Q, Jørgensen A-MK, Hammerstrøm K, Sathe N. Searching for studies: a guide to information retrieval for Campbell systematic reviews. Campbell Syst Rev. 2017;13(1):1-73. DOI: http://dx.doi.org/10.4073/cmg.2016.1.

101. Iansavichene AE, Sampson M, McGowan J, Ajiferuke IS. Should systematic reviewers search for randomized, controlled trials published as letters? Ann Intern Med. 2008 May 6;148(9):714-5. DOI: http://dx.doi.org/10.7326/00034819-148-9-200805060-00023.

102. Cooper C, Booth A, Varley-Campbell J, Britten N, Garside R. Defining the process to literature searching in systematic reviews: a literature review of guidance and supporting studies. BMC Med Res Methodol. 2018 Aug 14;18(1):85. DOI: http:/ / dx.doi.org/10.1186/s12874-018-0545-3.

103. Craven J, Levay P. Recording database searches for systematic reviews - what is the value of adding a narrative to peer-review checklists? a case study of NICE interventional procedures guidance. Evid Based Libr Inf 
Pract. 2011;6(4):72-87. DOI:

http://dx.doi.org/10.18438/B8CD09.

104. Scottish Intercollegiate Guidelines Network (SIGN). Search filters [Internet]. The Network; 2011 [cited 15 Jan 2021].

<https://www.sign.ac.uk/what-we-

do/methodology/search-filters/>.

105. Karagiannis T, Paschos P, Paletas K, Matthews DR, Tsapas

A. Dipeptidyl peptidase- 4 inhibitors for treatment of type 2 diabetes mellitus in the clinical setting: systematic review and meta-analysis. BMJ. 2012 Mar 12;344:e1369. DOI:

http://dx.doi.org/10.1136/bmj.e1369.

106. Lefebvre C, Glanville J, Beale S, Boachie C, Duffy S, Fraser C, Harbour J, McCool R, Smith L. Assessing the performance of methodological search filters to improve the efficiency of evidence information retrieval: five literature reviews and a qualitative study. Health Technol Assess. 2017 Nov;21(69):1148. DOI: http://dx.doi.org/10.3310/hta21690.

107. Damarell RA, May N, Hammond S, Sladek RM, Tieman JJ. Topic search filters: a systematic scoping review. Health Inf Libr J. 2019 Mar;36(1):4-40. DOI: http://dx.doi.org/10.1111/hir.12244.

108. McKibbon KA, Wilczynski NL, Haynes RB, Hedges T.

Retrieving randomized controlled trials from MEDLINE: a comparison of 38 published search filters. Health Inf Libr J. 2009 Sep;26(3):187-202. DOI: http://dx.doi.org/10.1111/j.1471-1842.2008.00827.x.

109. InterTASC Information Specialists' Sub-Group. The InterTASC Information Specialists' Sub-Group search filter resource [Internet]. The Sub-Group; 2020 [cited 1 Feb 2020]. $<$ https://sites.google.com/a/york.ac.uk/issg-search-filtersresource>.

110. Health Information Research Unit. Search filters for MEDLINE in Ovid syntax and the PubMed translation [Internet]. The Unit; 2016 [cited 1 Feb 2020]. <http://hiru.mcmaster.ca/hiru/HIRU_Hedges_MEDLINE_ Strategies.aspx $>$.

111. Waters E, de Silva-Sanigorski A, Hall BJ, Brown T, Campbell KJ, Gao Y, Armstrong R, Prosser L, Summerbell CD. Interventions for preventing obesity in children. Cochrane Database Syst Rev. 2011 Dec 7(12):Cd001871. DOI: http://dx.doi.org/10.1002/14651858.CD001871.pub3.

112. Cahill K, Lancaster T. Workplace interventions for smoking cessation. Cochrane Database Syst Rev. 2014 Feb
26(2):Cd003440. DOI:

http:/ / dx.doi.org/10.1002/14651858.CD003440.pub4.

113. Freak-Poli RL, Cumpston M, Peeters A, Clemes SA.

Workplace pedometer interventions for increasing physical activity. Cochrane Database Syst Rev. 2013 Apr 30(4):Cd009209. DOI:

http://dx.doi.org/10.1002/14651858.CD009209.pub2.

114. Dobbins M, Husson H, DeCorby K, LaRocca RL. Schoolbased physical activity programs for promoting physical activity and fitness in children and adolescents aged 6 to 18 . Cochrane Database Syst Rev. 2013 Feb 28(2):Cd007651. DOI: http:/ / dx.doi.org/10.1002/14651858.CD007651.pub2.

115. Guerra PH, Nobre MR, da Silveira JA, Taddei JA. Schoolbased physical activity and nutritional education interventions on body mass index: a meta-analysis of randomised community trials - project PANE. Prev Med. 2014 Apr;61:81-9. DOI: http://dx.doi.org/10.1016/j.ypmed.2014.01.005.

116. Jaime PC, Lock K. Do school based food and nutrition policies improve diet and reduce obesity? Prev Med. 2009 Jan;48(1):45-53. DOI:

http://dx.doi.org/10.1016/j.ypmed.2008.10.018.

117. Thomas RE, McLellan J, Perera R. School-based programmes for preventing smoking. Cochrane Database Syst Rev. 2013 Apr 30(4):Cd001293. DOI: http://dx.doi.org/10.1002/14651858.CD001293.pub3.

118. Foxcroft D, Ireland D, Lowe G, Breen R. Primary prevention for alcohol misuse in young people. Cochrane Database Syst Rev. 2011 Sep 7(9):Cd003024. DOI: http:/ / dx.doi.org/10.1002/14651858.CD003024.pub2.

119. Wolfenden L, Jones J, Williams CM, Finch M, Wyse RJ, Kingsland M, Tzelepis F, Wiggers J, Williams AJ, Seward K, Small T, Welch V, Booth D, Yoong SL. Strategies to improve the implementation of healthy eating, physical activity and obesity prevention policies, practices or programmes within childcare services. Cochrane Database Syst Rev. 2016 Oct 4;10:Cd011779. DOI: http:/ / dx.doi.org/10.1002/14651858.CD011779.pub2.

120. Wolfenden L, Nathan NK, Sutherland R, Yoong SL, Hodder RK, Wyse RJ, Delaney T, Grady A, Fielding A, Tzelepis F, Clinton-McHarg T, Parmenter B, Butler P, Wiggers J, Bauman A, Milat A, Booth D, Williams CM. Strategies for enhancing the implementation of school-based policies or 
practices targeting risk factors for chronic disease. Cochrane Database Syst Rev. 2017 Nov 29;11:Cd011677. DOI: http:/ /dx.doi.org/10.1002/14651858.CD011677.pub2.

121. Wolfenden L, Goldman S, Stacey FG, Grady A, Kingsland M, Williams CM, Wiggers J, Milat A, Rissel C, Bauman A, Farrell MM, Legare F, Ben Charif A, Zomahoun HTV, Hodder RK, Jones J, Booth D, Parmenter B, Regan T, Yoong SL. Strategies to improve the implementation of workplacebased policies or practices targeting tobacco, alcohol, diet, physical activity and obesity. Cochrane Database Syst Rev. 2018 Nov 14;11:CD012439. DOI: http://dx.doi.org/10.1002/14651858.CD012439.pub2.

122. White CM, Ip S, McPheeters M, Carey TS, Chou R, Lohr KN, Robinson K, McDonald K, Whitlock E. Using existing systematic reviews to replace de novo processes in conducting comparative effectiveness reviews. methods guide for effectiveness and comparative effectiveness reviews. Rockville, MD: AHRQ Methods for Effective Health Care; 2008.

123. Lopez-Olivo MA, Tayar JH, Martinez-Lopez JA, Pollono EN, Cueto JP, Gonzales-Crespo MR, Fulton S, Suarez-Almazor ME. Risk of malignancies in patients with rheumatoid arthritis treated with biologic therapy: a meta-analysis. JAMA. 2012 Sep 5;308(9):898-908. DOI: http://dx.doi.org/10.1001/2012.jama.10857.

124. Sampson M, Shojania KG, Garritty C, Horsley T, Ocampo M, Moher D. Systematic reviews can be produced and published faster. J Clin Epidemiol. 2008 Jun;61(6):531-6. DOI: http://dx.doi.org/10.1016/j.jclinepi.2008.02.004.

125. Shojania KG, Sampson M, Ansari MT, Ji J, Doucette S, Moher D. How quickly do systematic reviews go out of date? a survival analysis. Ann Intern Med. 2007 Aug 21;147(4):22433. DOI: http://dx.doi.org/10.7326/0003-4819-147-4200708210-00179.

126. Shojania KG, Sampson M, Ansari MT, Ji J, Garritty C, Doucette S, Rader T, Moher D. Updating systematic reviews: AHRQ publication no 07-0087. AHRQ Technical Reviews [Internet]. 16. Agency for Healthcare Research and Quality; 2007 [cited 1 Feb 2020].

<http:/ / www.ncbi.nlm.nih.gov/books/NBK44099/pdf/TO C.pdf>.

127. Bhaskar V, Chan HL, MacEachern M, Kripfgans OD. Updates on ultrasound research in implant dentistry: a systematic review of potential clinical indications.

Dentomaxillofac Radiol. 2018 Jul;47(6):20180076. DOI:

http://dx.doi.org/10.1259/dmfr.20180076.

128. Beller EM, Chen JK, Wang UL, Glasziou PP. Are systematic reviews up-to-date at the time of publication? Syst Rev. 2013 May 28;2:36. DOI: http://dx.doi.org/10.1186/2046-4053-236.

129. Velez MP, Hamel C, Hutton B, Gaudet L, Walker M, Thuku M, Cobey KD, Pratt M, Skidmore B, Smith GN. Care plans for women pregnant using assisted reproductive technologies: a systematic review. Reprod Health. 2019 Jan 29;16(1):9. DOI: http:/ / dx.doi.org/10.1186/s12978-019-0667-

130. Relevo R, Paynter R. Peer review of search strategies. AHRQ methods for effective health care [Internet]. Rockville (MD): Agency for Healthcare Research and Quality; 2012 [cited 1 Feb 2020]. <https://www.ncbi.nlm.nih.gov/books/NBK98353/>.

131. Spry C, Mierzwinski-Urban M. The impact of the peer review of literature search strategies in support of rapid review reports. Res Synth Methods. 2018 Dec;9(4):521-6. DOI: http://dx.doi.org/10.1002/jrsm.1330.

132. Tsamalaidze L, Stauffer JA, Brigham T, Asbun HJ. Postsplenectomy thrombosis of splenic, mesenteric, and portal vein (PST-SMPv): a single institutional series, comprehensive systematic review of a literature and suggested classification. Am J Surg. 2018 Dec;216(6):1192204. DOI: http://dx.doi.org/10.1016/j.amjsurg.2018.01.073.

133. Banno M, Harada $Y$, Taniguchi M, Tobita R, Tsujimoto $H$, Tsujimoto Y, Kataoka Y, Noda A. Exercise can improve sleep quality: a systematic review and meta-analysis. PeerJ. 2018;6:e5172. DOI: http://dx.doi.org/10.7717/peerj.5172.

134. Barakat S, Boehmer K, Abdelrahim M, Ahn S, Al-Khateeb AA, Villalobos NA, Prokop L, Erwin PJ, Fleming K, Serrano V, Spencer-Bonilla G, Murad MH. Does health coaching grow capacity in cancer survivors? a systematic review. Popul Health Manag. 2018 Feb;21(1):63-81. DOI: http://dx.doi.org/10.1089/pop.2017.0040.

135. Qi X, Yang M, Ren W, Jia J, Wang J, Han G, Fan D. Find duplicates among the PubMed, EMBASE, and Cochrane Library databases in systematic review. PLoS One. 2013;8(8):e71838. DOI: http:/ / dx.doi.org/10.1371/journal.pone.0071838. 
136. Bramer WM, Giustini D, de Jonge GB, Holland L, Bekhuis T. De-duplication of database search results for systematic reviews in EndNote. J Med Libr Assoc. 2016 Jul;104(3):240-3. DOI: http:// dx.doi.org/10.3163/1536-5050.104.3.014.

137. Rathbone J, Carter M, Hoffmann T, Glasziou P. Better duplicate detection for systematic reviewers: evaluation of systematic review assistant-deduplication module. Syst Rev. 2015 Jan 14;4:6. DOI: http:// dx.doi.org/10.1186/2046-40534-6.

138. Kwon Y, Lemieux M, McTavish J, Wathen N. Identifying and removing duplicate records from systematic review searches. J Med Libr Assoc. 2015 Oct;103(4):184-8. DOI: http://dx.doi.org/10.3163/1536-5050.103.4.004.

139. Tricco AC, Lillie E, Zarin W, O’Brien KK, Colquhoun $\mathrm{H}_{\text {, }}$ Levac D, Moher D, Peters MDJ, Horsley T, Weeks L, Hempel S, Akl EA, Chang C, McGowan J, Stewart L, Hartling L, Aldcroft A, Wilson MG, Garritty C, Lewin S, Godfrey CM, Macdonald MT, Langlois EV, Soares-Weiser K, Moriarty J, Clifford T, Tuncalp O, Straus SE. PRISMA extension for Scoping Reviews (PRISMA-ScR): checklist and explanation. Ann Intern Med. 2018 Oct 2;169(7):467-73. DOI: http://dx.doi.org/10.7326/M18-0850.

140. Hutton B, Salanti G, Caldwell DM, Chaimani A, Schmid CH, Cameron C, Ioannidis JP, Straus S, Thorlund K, Jansen JP, Mulrow C, Catala-Lopez F, Gotzsche PC, Dickersin K, Boutron I, Altman DG, Moher D. The PRISMA extension statement for reporting of systematic reviews incorporating network meta-analyses of health care interventions: checklist and explanations. Ann Intern Med. 2015 Jun 2;162(11):77784. DOI: http://dx.doi.org/10.7326/M14-2385.

141. Stewart LA, Clarke M, Rovers M, Riley RD, Simmonds M, Stewart G, Tierney JF, PRISMA-IPD Development Group. Preferred Reporting Items for Systematic Review and MetaAnalyses of individual participant data: the PRISMA-IPD Statement. JAMA. 2015 Apr 28;313(16):1657-65. DOI: http://dx.doi.org/10.1001/jama.2015.3656.

142. Haddaway NR, Macura B, Whaley P, Pullin AS. ROSES RepOrting standards for Systematic Evidence Syntheses: pro forma, flow-diagram and descriptive summary of the plan and conduct of environmental systematic reviews and systematic maps. Environ Evid. 2018 7(1):7. DOI: http://dx.doi.org/10.1186/s13750-018-0121-7.
143. Stansfield C, O'Mara-Eves A, Thomas J. Text mining for search term development in systematic reviewing: a discussion of some methods and challenges. Res Synth Methods. 2017 Sep;8(3):355-65. DOI: http://dx.doi.org/10.1002/jrsm.1250.

144. Hausner E, Guddat C, Hermanns T, Lampert U, Waffenschmidt S. Prospective comparison of search strategies for systematic reviews: an objective approach yielded higher sensitivity than a conceptual one. J Clin Epidemiol. 2016 Sep;77:118-24. DOI: http://dx.doi.org/10.1016/j.jclinepi.2016.05.002.

145. Paynter R, Banez LL, Berliner E, Erinoff E, Lege-Matsuura J, Potter S, Uhl S. EPC Methods: an exploration of the use of text-mining software in systematic reviews [Internet]. Rockville, MD: Agency for Healthcare Research and Quality; 2016 [cited 3 Feb 2020].

<https://www.ncbi.nlm.nih.gov/books/NBK362044/>. 


\section{AUTHORS' AFFILIATIONS}

Melissa L. Rethlefsen, MSLS, AHIP* (corresponding author), mlrethlefsen@gmail.com, https://orcid.org/0000-0001-5322-9368, Executive Director and Professor, Health Sciences Library \& Informatics Center, University of New Mexico

* Formerly at the Spencer S. Eccles Health Sciences Library, University of Utah and Health Science Center Libraries, George A. Smathers Libraries, University of Florida.

Shona Kirtley, MA, MSc, shona.kirtley@csm.ox.ac.uk, https://orcid.org/0000-0002-7801-5777, Senior Research Information Specialist, UK EQUATOR Centre, Centre for Statistics in Medicine (CSM), Nuffield Department of Orthopaedics, Rheumatology and Musculoskeletal Sciences (NDORMS), University of Oxford, Botnar Research Centre, Oxford, United Kingdom

Siw Waffenschmidt, PhD, siw.waffenschmidt@iqwig.de, https://orcid.org/0000-0001-6860-6699, Head of the Information Management Unit, Institute for Quality and Efficiency in Health Care, Cologne, Germany

Ana Patricia Ayala, MISt, AHIP, anap.ayala@utoronto.ca, https://orcid.org/0000-0002-3613-2270, Research Services Librarian, Gerstein Science Information Centre, University of Toronto, Toronto, ON, Canada

David Moher, PhD, dmoher@ohri.ca, https://orcid.org/0000-00032434-4206, Centre for Journalology, Clinical Epidemiology Program, Ottawa Hospital Research Institute, The Ottawa Hospital, General Campus, Centre for Practice Changing Research Building, Ottawa, ON, Canada

Matthew J. Page, PhD, matthew.page@monash.edu, https://orcid.org/0000-0002-4242-7526, Research Fellow, School of Public Health and Preventive Medicine, Monash University, Melbourne, Australia

Jonathan B. Koffel, MSI, jbkoffel@umn.edu, https://orcid.org/00000003-1723-5087, Emerging Technology and Innovation Strategist, University of Minnesota, Minneapolis, MN

PRISMA-S Group (see “Acknowledgments") 